\title{
Der ältere Krebspatient - Herausforderungen im Krankenhaus und in der Praxis
}

\author{
Carsten Bokemeyer $^{a}$ Reinhard Busse $^{b}$ Jutta Engel ${ }^{c} \quad$ Alexander Gebauer $^{d}$ Michael Hallek ${ }^{e}$ \\ Volker Heinemann $^{f}$ Diana Lüftner ${ }^{g}$ Bernhard Wörmann ${ }^{\text {h }}$
}

all. Medizinische Klinik und Poliklinik, Universitätsklinikum Hamburg-Eppendorf, Hamburg, Deutschland;

${ }^{b}$ Fachgebiet Management im Gesundheitswesen, Fakultät Wirtschaft \& Management, Technische Universität Berlin, Berlin, Deutschland;

c Tumorregister München (TRM) des Tumorzentrums München (TZM), Institut für Medizinische Informationsverarbeitung,

Biometrie und Epidemiologie (IBE), Ludwig-Maximilians-Universität (LMU) München, München, Deutschland;

d Zentralstelle der Krebsregistrierung, Institut für Community Medicine, Abteilung Versorgungsepidemiologie und Community Health, Universitätsmedizin Greifswald, Greifswald, Deutschland;

e Klinik I für Innere Medizin und CIO Köln Bonn, Universitätsklinikum Köln, Köln, Deutschland;

${ }^{f}$ Medizinische Klinik und Poliklinik III, Klinikum der Ludwig-Maximilians-Universität (LMU) München, München, Deutschland;

gMedizinische Klinik mit Schwerpunkt Hämatologie, Onkologie und Tumorimmunologie, Charité - Universitätsmedizin Berlin, Campus Benjamin Franklin, Berlin, Deutschland;

h Medizinische Klinik mit Schwerpunkt Hämatologie, Onkologie und Tumorimmunologie, Charité - Universitätsmedizin Berlin, Campus Virchow-Klinikum, Berlin, Deutschland

\section{Epidemiologie der Krebserkrankungen bei älteren Patienten}

\section{Referentin: Jutta Engel, München}

Die Epidemiologie befasst sich mit der Verbreitung sowie den Ursachen und Folgen gesundheitsbezogener Zustände in der Bevölkerung, wobei die Inzidenz und Mortalität (in diesem Fall von Krebserkrankungen) durch verschiedene Faktoren beeinflusst werden. Dazu gehören unter anderem genetische Merkmale, äußere Einflüsse (Umwelt, Lifestyle) und als wesentlicher Faktor auch das Lebensalter.

Die Weltgesundheitsorganisation (WHO) geht von jährlich 14 Millionen Krebserkrankungen und etwa 8 Millionen krebsbedingten Todesfällen weltweit aus [1]. Die Industrienationen sind nach den WHO-Erhebungen deutlich stärker von Krebserkrankungen betroffen, wobei zu beachten ist, das in diesen Ländern die Inzidenzen wohl vollständiger erfasst werden dürften als in wirtschaftlich ärmeren Regionen. Die weltweit 5 häufigsten Krebserkrankungen bei Männern sind Lungen-, Prostata- und kolorektale Karzinome (zusammen 42\%), gefolgt von Magen- und Leberkrebs. Bei Frauen sind Mammakarzinome (25\%) am häufigsten, gefolgt von Karzinomen des Darmes (9\%), der Geschlechtsorgane (Zervix uteri) und des Magens. Bei den Mortalitätsraten stehen bei den Männern Lungenkarzinome an erster Stelle (24\% Anteil an der Gesamtmortalität) und bei den Frauen Brustkrebs und Lungenkrebs mit Anteilen von $15 \%$ bzw. $14 \%$.
In Deutschland ging das Robert Koch-Institut für das Jahr 2014 von 476120 neu aufgetretenen Krebserkrankungen aus (249 160 Männer und 226960 Frauen), wobei Männer am häufigsten an Prostata-, Lungen- und Darmkrebs erkrankten (23\%, 14\% bzw. 13\%) und Frauen an Brust-, Darm und Lungenkrebs (31\%, 12\% bzw. 9\%) [2]. Das maligne Melanom ist bei beiden Geschlechtern mit einer Inzidenz von 4-5\% im weltweiten Vergleich relativ häufig vertreten. Bei den Krebssterbefällen (Gesamtzahl für Deutschland im Jahr 2014: 222972 Verstorbene) ist bei Männern der Lungenkrebs führend und bei Frauen der Brustkrebs. Das Pankreaskarzinom steht in Deutschland bei beiden Geschlechtern an vierter Stelle der Krebstodesursachen und damit im weltweiten Rangvergleich relativ weit vorn.

Das Alter ist ein Risikofaktor für die Entwicklung von Krebserkrankungen, womöglich gar der wichtigste Risikofaktor überhaupt. Mit zunehmendem Lebensalter lässt die genetische Reparaturaktivität der Zellen nach, was zu genetischer Instabilität und gehäuftem Auftreten von Mutationen führt [3]. Dies begünstigt das Auftreten von Tumoren. Wie die Bevölkerungspyramide für Deutschland zeigt, kommen die geburtenstarken Jahrgänge nach und nach in das für die Krebsentstehung relevante Lebensalter. Dies erklärt die hohe Zahl an Krebserkrankungen, die in München und Umgebung in den Jahren 2008-2012 bei 577 pro 100000 Männer und 521 pro 100000 Frauen lag [4]. Jedoch sind in Deutschland Krebserkrankungen auch altersstandardisiert vergleichsweise häufiger als in einem Schwellenland wie z.B. Indien. 
Abb. 1. Altersverteilung (Säulen) und altersspezifische Inzidenz (Linien) von Krebsneuerkrankungen im Einzugsgebiet des TRM.

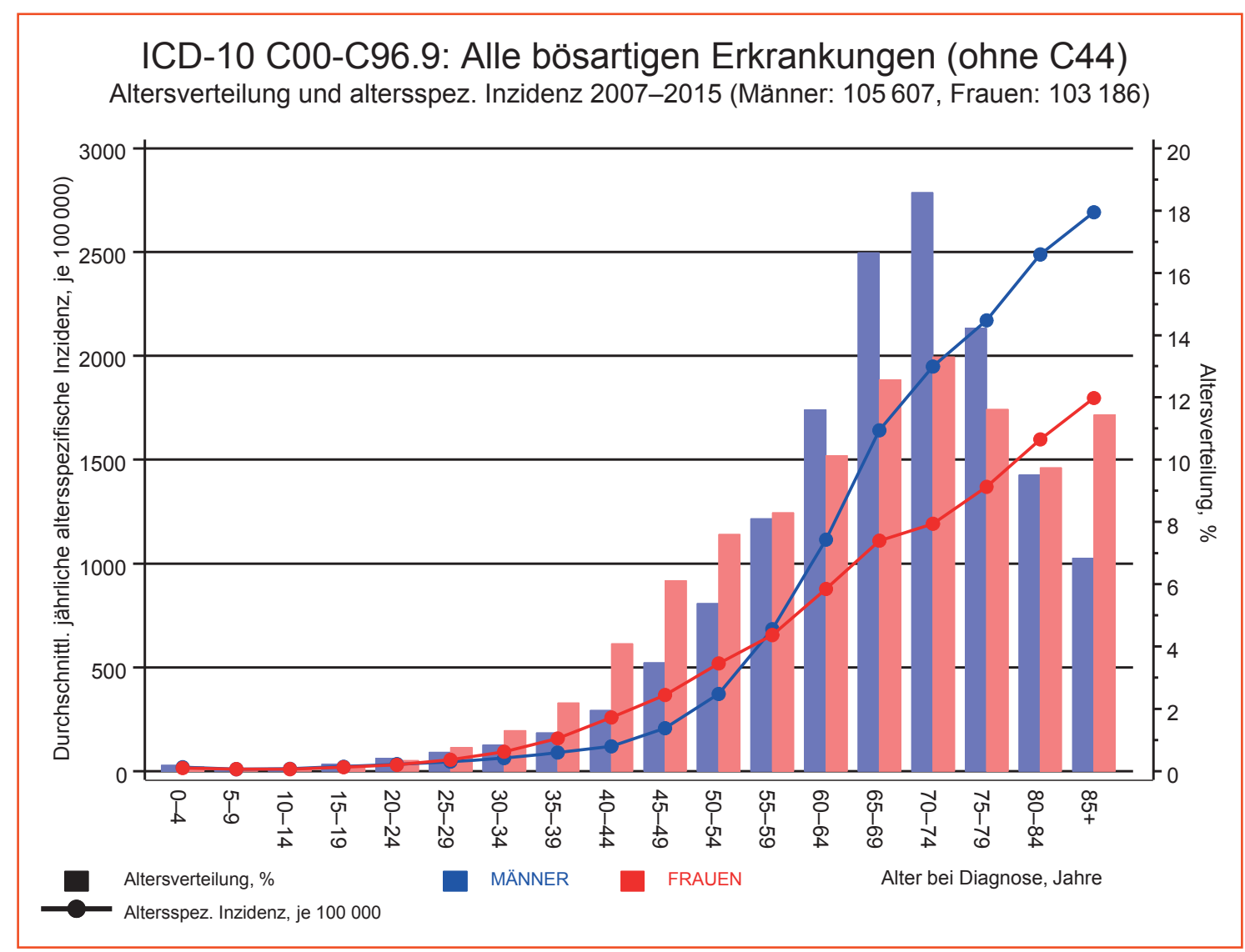

Unter Berücksichtigung der Altersstruktur lässt sich die Zahl der Krebsfälle für die nächsten Jahrzehnte projizieren [5]. Demnach betreffen in Deutschland im Jahr 2030 die 5 häufigsten Tumordiagnosen (beide Geschlechter) die Prostata, die Brustdrüse, die Lunge, den Darm und die Haut. Die statistische Vorhersage geht ferner von einer Zunahme der Mortalität an Lungen- und Bauchspeicheldrüsenkrebs aus sowie von einer leichten Abnahme der Sterblichkeit an Darm-, Brust- und Prostatakrebs [5], worin sich auch therapeutische Fortschritte zu spiegeln scheinen.

\section{Krebs bei Älteren am Beispiel verschiedener Krebsentitäten}

Einen Einblick in die Epidemiologie von Krebserkrankungen speziell der älteren Bevölkerung ermöglicht unter anderem das Tumorregister München (TRM), das etwa 38\% der bayerischen Bevölkerung (4,8 Millionen Einwohner) abdeckt. Vom TRM werden pro Jahr etwa 25000 Patienten mit invasivem Karzinom dokumentiert. Die zugehörigen Statistiken und tumorspezifischen Auswertungen können im TRM [6] unter www.tumorregister-muenchen. de eingesehen werden. In Abbildung 1 sind die altersspezifische Inzidenz aller vom TRM neu erfassten bösartigen invasiven Erkrankungen der Jahre 2007-2015 und die Altersverteilung aufgeführt. Der Kurvenverlauf zeigt deutlich den Anstieg der Krebserkrankungen im Alter. Bei der Krebserstdiagnose sind Männer im Median 69,8 Jahre alt und Frauen 66,7 Jahre. Dabei ist zu beachten, dass die sich verändernde Bevölkerungsstruktur zwar Einfluss auf die Altersverteilung hat (und damit auf die absoluten und prozentualen Zahlenangaben), nicht jedoch auf die altersspezifische Inzi- denz (das «Krebsrisiko» - in der Abbildung als Linien dargestellt): Dass heute Brustkrebs häufiger diagnostiziert wird als noch in den 1970er Jahren, liegt also nicht etwa an einem gestiegenen Krebsrisiko, sondern daran, dass ältere Frauen heute einen größeren Anteil an der Gesamtbevölkerung haben.

\section{Altersabhängigkeit am Beispiel des nichtkleinzelligen Lungenkarzinoms}

Die Daten des TRM lassen unter anderem eine Auswertung verschiedener Prognoseparameter in Abhängigkeit vom Alter des Patienten zu [7]. So zeigte sich bei Patienten mit nichtkleinzelligem Lungenkarzinom (NSCLC) mit Erstdiagnose ab dem Jahr 2010, dass das progressionsfreie Überleben bei Menschen $\geq 70$ Jahren ähnlich ist wie bei den Jüngeren. Dies gilt auch bei Berücksichtigung des EGFR-Status (EGFR = epidermaler Wachstumsfaktorrezeptor) (Abb. 2), wobei ältere Patienten mit positivem EGFRStatus lediglich zu 7,6\% in der Gesamtkohorte von 669 Patienten vertreten waren, unter 70-Jährige immerhin mit knapp 12\%. Die weitere Entwicklung des progressionsfreien Überlebens und des Gesamt- bzw. relativen Überlebens im Hinblick auf neue Therapieoptionen bleibt abzuwarten.

\section{Relatives Überleben bei kolorektalen Karzinomen vergleichbar}

Bei der Betrachtung von Überlebenszeitkurven muss - wie in Abbildung 3 - zwischen dem Gesamtüberleben und dem relativen Überleben im Vergleich zur altersgleichen, nicht an Krebs erkrankten Bevölkerung unterschieden werden. So fiel das Gesamtüberle- 


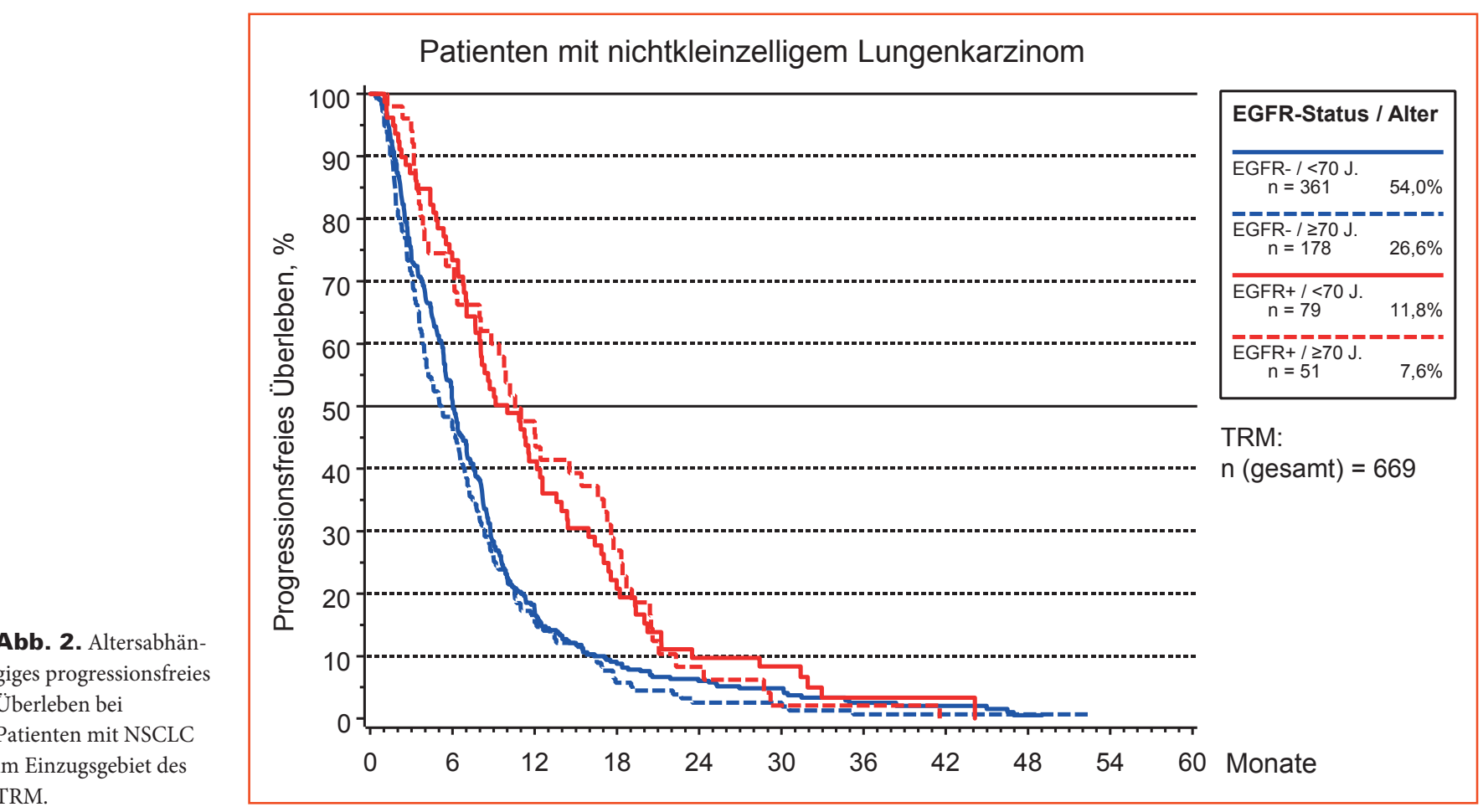

ben bei Patienten mit kolorektalen Tumoren in den höheren $\mathrm{Al}$ tersgruppen im Vergleich zu den jüngeren Gruppen erwartungsgemäß deutlich geringer aus (Abb. 3 oben), im relativen Überleben (als Schätzung für das tumorspezifische Überleben) zeigten die verschiedenen Altersgruppen dagegen einen recht ähnlichen Verlauf (Abb. 3 unten). In die Analyse wurden Patienten mit Erstdiagnose eines kolorektalen Karzinoms (KRK) ab dem Jahr 1998 aufgenommen. Dass die Gruppe der über 80-jährigen Patienten eine anfänglich geringere Überlebenswahrscheinlichkeit hatte, mag der Tatsache geschuldet sein, dass ein Teil dieser Patienten aufgrund von Komorbiditäten und anderen Ausschlussfaktoren keine Therapie erhielt.

Bei Berechnung der Überlebenswahrscheinlichkeit nach der Landmark-Methode [9] werden solche altersbedingten Einflussfaktoren (z.B. die vom Alter abhängige Indikation zur Operation) berücksichtigt. Die Analyse des bedingten (relativen) Überlebens erfolgt dann bei Patienten ab einem definierten Cut-off-Zeitpunkt, z.B. mindestens 6 Monate nach Diagnosestellung und bis dahin nicht verstorben. Sowohl bei einem Cut-off nach 6 Monaten als auch bei einem Cut-off nach 12 Monaten zeigten die älteren Patienten ein vergleichbares und somit altersunabhängiges relatives (d.h. tumorspezifisches) Überleben. Es ist deshalb davon auszugehen, dass alte Patienten, die (bei ausreichender Fitness) eine Krebstherapie erhalten, von dieser in ähnlichem Maße profitieren wie jüngere Menschen.

\section{Überlebensraten bei Brustkrebs auch bei älteren Frauen gut}

Bei der Auswertung der Registerdaten zum Mammakarzinom hat das TRM eine Aufteilung in 3 Altersklassen ( $<50$ Jahre, 50-69 Jahre, $\geq 70$ Jahre) vorgenommen. Eingeschlossen wurden über 34000 Frauen mit primärem Mammakarzinom (M0) aus den Jah- ren 2004-2016. Im 10-Jahres-Gesamtüberleben schnitt die älteste Altersklasse wie zu erwarten am schlechtesten ab. Das relative Überleben war bei diesen (nicht metastasierten) Tumoren insgesamt gut, wobei die mittlere Altersgruppe das beste Langzeitüberleben erreichte. Bei Frauen ab 70 Jahren war das relative Überleben jedoch um etwa 10\% geringer, weshalb eine weitere Analyse unter Berücksichtigung von 5 intrinsischen Tumorsubtypen erfolgte (Abb. 4). Tripel-negative Mammakarzinome waren mit einem geringeren relativen Überleben verknüpft, insbesondere in der Gruppe der $\geq 70$-jährigen Frauen. Dagegen zeigten Karzinome vom Typ luminal-A-like einen insgesamt günstigeren Verlauf, der zudem keine große auffällige Altersbezogenheit erkennen ließ.

Als weiterer Parameter wurde die Zeit bis zur Metastasierung (kumulative Inzidenz unter Berücksichtigung von «competing risks») gewählt und in Abhängigkeit zum Tumorsubtyp und den 3 Altersgruppen gesetzt. Die Unterschiede zwischen den Altersgruppen waren diesbezüglich nicht gravierend und erklären somit nicht den zuvor gezeigten Nachteil im Überleben der älteren Patientinnen. Womit die schlechtere Prognose der älteren Frauen zu begründen ist - etwa wegen Modifikation bzw. Verzicht auf aggressive Therapien - ist den vorliegenden Daten somit nicht zu entnehmen und bedarf weiterer epidemiologischer Erhebungen.

\section{Im Alter steigen Leukämien stark an}

Das Robert Koch-Institut weist für die Leukämien einen alterstypischen Anstieg aus [2]. Männer erkranken im Median im Alter von 71 Jahren und Frauen im Alter von 73 Jahren an einer Leukämie. Die vom TRM separat ausgewertete chronisch lymphatische Leukämie (CLL) hat ihren Gipfel im höheren Lebensalter und die altersspezifische Inzidenz steigt ab dem 70. Lebensjahr noch einmal deutlich an. Das relative 10-Jahres-Überleben liegt bei Män- 


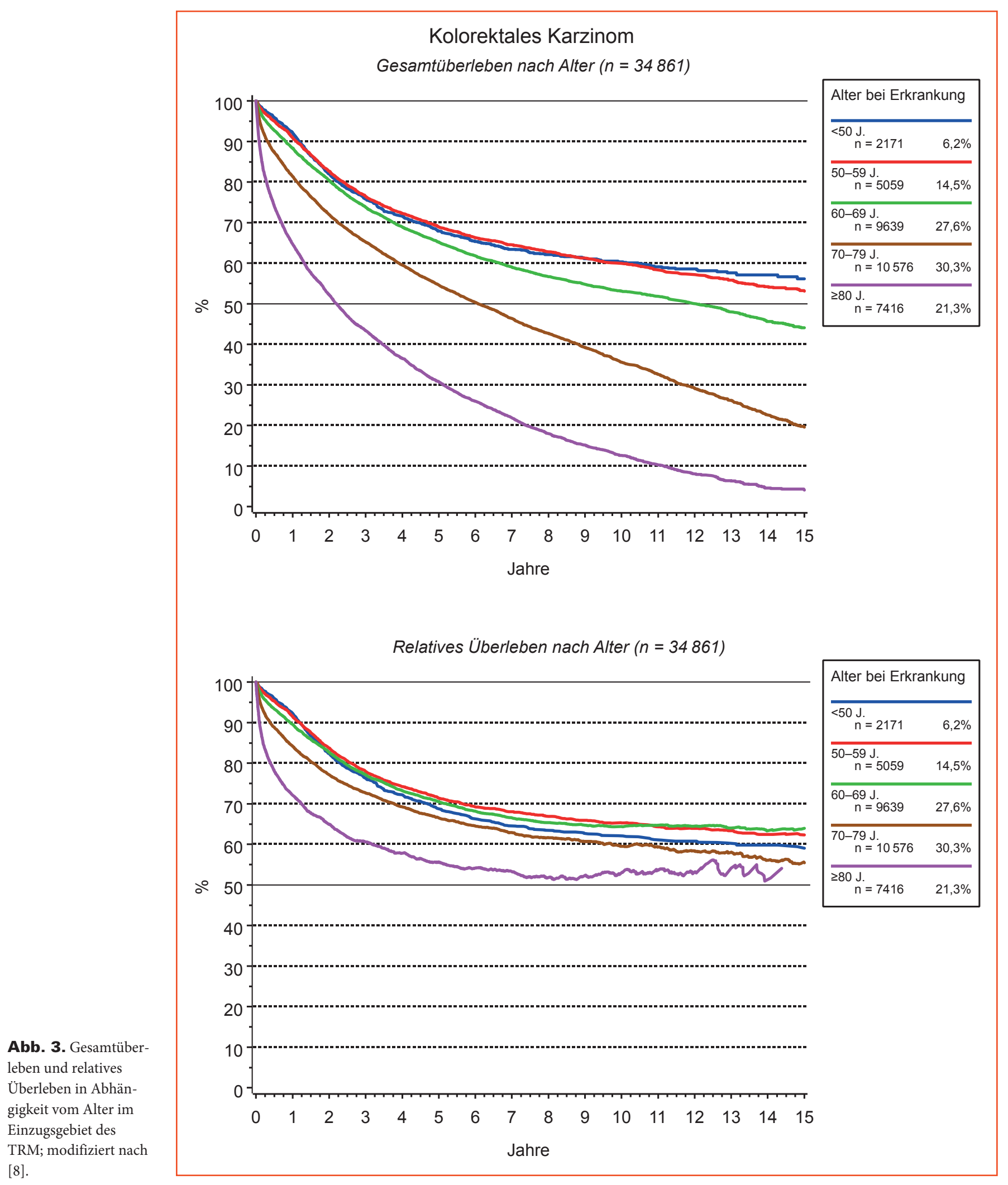

nern und Frauen bei etwa 60-65\% für die Diagnosejahre 19982015. Differenziert nach Altersgruppen schnitten die $\geq 75$-Jährigen allerdings deutlich schlechter ab, wofür die epidemiologischen Daten zunächst keine Erklärung liefern.
Die Zusammenhänge zwischen Lebensalter und Krebserkrankung sind komplex, zumal der Risikofaktor Alter bei den Tumorentitäten verschieden stark ins Gewicht fällt. Auch für den Therapieerfolg und die Prognose der Erkrankung ist die Bedeutung des chronologischen/biologischen Alters nur schwer abzuschätzen, 


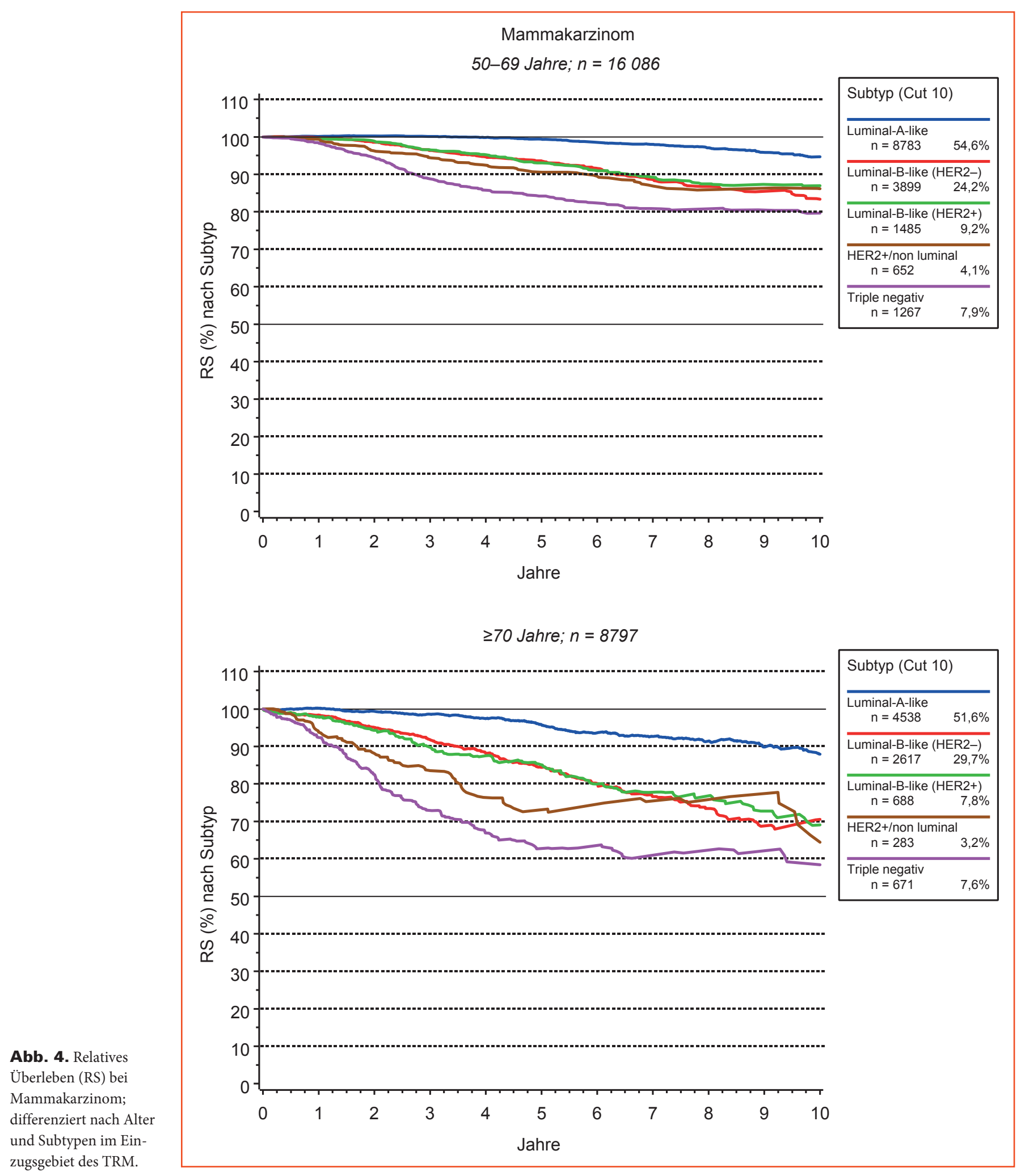

zumal auf vielen Ebenen Wechselwirkungen bestehen. Aussagen zum Einfluss des Alters auf das Krebsgeschehen erfordern deshalb eine differenzierte Sicht auf das Thema sowie aufwändige statistische (multivariate) Analysen unter Einbeziehung von Therapien, Kovariablen und Komorbiditäten. Oncol Res Treat 2018;41(suppl 3):2-26
Ist Früherkennung bei älteren Menschen sinnvoll?

Referent: Bernhard Wörmann, Berlin

Zwar gibt es keine Früherkennungsprogramme explizit für ältere Menschen, jedoch stellt sich die Frage, ob die vorhandenen 
Angebote im Hinblick auf die sich ändernde Bevölkerungsstruktur mit Zunahme des Anteils älterer Menschen noch angemessen und sinnvoll sind, auch wenn dies bei uns im Unterschied zu anderen Ländern derzeit nicht im Fokus der politischen Diskussion steht.

Die WHO hat 1968 für die Etablierung von Früherkennungsprogrammen 10 Kriterien formuliert [10]. So sollte nur auf Krankheiten gescreent werden, die ein relevantes medizinisches Problem sind - das ist bei onkologischen Erkrankungen zweifelsfrei gegeben, wobei einige Tumorentitäten zwar von hoher gesundheitlicher Relevanz sind, aber zu selten auftreten, um für ein Screening infrage zu kommen. Anwendbar auf die Onkologie verlangt die WHO, dass die zu screenende Erkrankung bzw. der gesundheitsgefährdende Zustand einen latenten Verlauf zeigt, um dieses Zeitfenster für die Früherkennung nutzen zu können. Beim Mammakarzinom wurde diese Zeitspanne zwischen mammografisch und klinisch entdecktem Tumor als 1,87-2,55 Jahre für Frauen im Alter von 40-49 Jahren und 3,0-3,7 Jahre für Frauen im Alter von 50-59 Jahren berechnet $[11,12]$. Andere Modelle berechnen für das Mammakarzinom eine Zeitspanne von 1,93 und 1,98 Jahren [13]. Des Weiteren muss die zu screenende Erkrankung in ihrem natürlichen Verlauf ausreichend verstanden sein und der gesamte Screeningprozess sollte sich verändernden Rahmenbedingungen anpassen können.

Auch wenn die Primärprävention - etwa eine ausgewogene Ernährung und ein gesunder Lebensstil - weiter an Bedeutung gewinnt, bleibt die Früherkennung zur Detektion von frühen Krebsstadien und Krebsvorstufen ein attraktives Konzept. Ziel der Früherkennung ist es, im Falle einer Krebserkrankung dem Betroffenen mit einer höheren Heilungschance und/oder mit einer weniger intensiven Therapie helfen zu können und seine Prognose zu verbessern.

\section{Kolorektales Karzinom: Früherkennung ohne obere \\ Altersbegrenzung}

Zur Früherkennung von KRK werden der immunologische Test auf okkultes Blut im Stuhl (FIT, seit 2017) sowie Endoskopien angeboten. Der Nutzen der Screeningmaßnahmen gemessen am Zugewinn an Lebensjahren pro 1000 gescreenten Personen ist nachgewiesen. Weniger invasive Methoden wie die flexible Sigmoidoskopie (alle 5 Jahre) schneiden diesbezüglich etwas schlechter ab als eine komplette Koloskopie alle 10 Jahre, insgesamt haben aber alle Methoden einen relativ ähnlichen Nutzen. Das gilt auch für den immunologischen Test 1-mal jährlich, der im Nutzenvergleich zur Koloskopie alle 10 Jahre fast mithalten kann. Zur Vermeidung kolorektal bedingter Todesfälle eignen sich ebenfalls alle Verfahren in ähnlicher Weise, mit leichten Vorteilen für die komplette Koloskopie.

Zur Krebsfrüherkennung des KRK gehört in Deutschland die digitale rektale Untersuchung jährlich ab dem 50. Lebensjahr, der Stuhltest auf okkultes Blut jährlich ab dem 50. Lebensjahr, wahlweise ab dem 55. Lebensjahr entweder 2-jährlich der Stuhltest auf okkultes Blut oder die totale Koloskopie alle 10 Jahre. Eine obere Altersbegrenzung gibt es für das Screening auf KRK nicht. Das entspricht den altersspezifischen Fallzahlen des Robert Koch-Instituts und der Gesellschaft der epidemiologischen Krebsregister in
Deutschland e.V. (GEKID) [14]. Jüngere Altersgruppen (55-64 Jahre) profitieren in ähnlichem Maße von der Früherkennung wie ältere Menschen (65-74 Jahre), wie für die flexible Sigmoidoskopie gezeigt worden ist [15]. In dieser Studie konnten die Karzinominzidenz und -mortalität um 27\% bzw. 18\% (jüngere Patienten) und um 35\% (ältere Patienten) durch das Screening gesenkt werden. Für noch ältere Patienten fehlen entsprechende Analysen, weshalb z.B. in Kanada alte Menschen von der Früherkennung ausgenommen sind. In Deutschland nimmt von den 60- bis 69-Jährigen etwa ein Viertel die Früherkennungskoloskopie in Anspruch (Erhebungszeitraum 2003-2010), bei den unter 60-Jährigen und den über 80-Jährigen sind es jedoch nur etwa 10\% [16].

Besondere Regeln gelten für Personen mit familiärer Belastung. Verwandte ersten Grades sollten in einem Alter koloskopiert werden, das 10 Jahre vor der Erkrankung des Patienten liegt, spätestens aber im Alter von 40-45 Jahren [17, 18].

\section{Mammakarzinom: Früherkennung zwischen dem 50. und 69 Lebensjahr}

Zur Primärprävention von Mammakarzinomen gehört ein gesunder Lebensstil einschließlich einer Gewichtsreduktion im Falle von Adipositas. Die Brustkrebs-Früherkennung umfasst die Tastuntersuchung der Brust und die Mammografie. Gezeigt wurde unter anderem, dass das Mammografie-Screening von Frauen im Alter zwischen 50 und 74 Jahren sowohl in jährlichen als auch in 2-jährlichen Abständen das Risiko für brustkrebsbedingten Tod senken kann [19]. Jährliche Mammografien senken noch etwas stärker die Mortalität, verdoppeln aber nahezu das Risiko für falsch-positive Befunde. In den meisten Ländern hat sich deshalb der 2-jährige Turnus durchgesetzt, in Deutschland gilt dies für Frauen zwischen 50 und 69 Jahren. Die Beteiligung an diesem Programm liegt bei etwa 50\%. In den USA können Frauen bis zum Alter von 74 Jahren eine Früherkennungsmammografie erhalten. Das Angebot gilt dort bereits für Frauen ab 40 Jahren, wenn sie auf den Nutzen gegenüber dem Risiko einer Überdiagnostik hingewiesen worden sind [20]. In Deutschland sollte diskutiert werden, aufgrund der vorliegenden Fallzahlen [14] das Altersfenster nach oben zu öffnen.

Besondere Regeln gelten für Frauen mit familiärer Belastung. Hier werden eine genetische Beratung und bei Nachweis definierter Mutationen, z.B. in den BRCA1/2-Genen, der Einschluss in spezifische Früherkennungsprogramme empfohlen [21].

\section{Prostatakrebs: Prostataspezifisches Antigen nicht anerkannt}

Die digitale rektale Untersuchung ist ein etabliertes Verfahren zur Früherkennung von Prostatakrebs, senkt aber nicht die tumorbedingte Sterblichkeit. Der Stellenwert der Messung des prostataspezifischen Antigens (PSA) im Blut zur Detektion invasiver Karzinome ist seit Jahren in der Diskussion. Große randomisierte Studien [22-25] zur Senkung der Prostatakarzinom-spezifischen Mortalität durch Anwendung des PSA-Screenings (vs. Beobachtung) kommen zu uneinheitlichen Ergebnissen. In einer US-amerikanischen Studie [22] waren jährliche PSA-Bestimmungen eher nachteilig in Bezug auf die Mortalitätssenkung (Abb. 5), wohingegen in 


\begin{tabular}{|c|c|c|c|c|c|c|c|c|}
\hline $\begin{array}{l}\text { Erstautor / } \\
\text { Jahr }\end{array}$ & Studie & Patienten & Kontrolle & $\begin{array}{l}\text { Neue } \\
\text { Methode }\end{array}$ & $\mathrm{N}$ & $\begin{array}{l}\text { Prostata- } \\
\text { karzinom (HR) }\end{array}$ & $\begin{array}{l}\text { PK Morta- } \\
\text { lität (HR) }\end{array}$ & $\begin{array}{l}\text { ÜL } \\
(H R)\end{array}$ \\
\hline $\begin{array}{l}\text { Andriole, } \\
2009\end{array}$ & PLCO & $\begin{array}{l}\text { männlich, } \\
\text { 55-74 } \\
\text { Jahre }\end{array}$ & $\begin{array}{l}\text { Beobach- } \\
\text { tung }\end{array}$ & $\begin{array}{l}\text { PSA } \\
\text { jährlich }\end{array}$ & 76.693 & 6,1 vs 7,4 & $\begin{array}{l}1,13 \\
\text { n. s. }\end{array}$ & n.s. \\
\hline $\begin{array}{l}\text { Schröder, } \\
2009\end{array}$ & ERSPC & $\begin{array}{l}\text { männlich, } \\
\text { 55-69 } \\
\text { Jahre }\end{array}$ & $\begin{array}{l}\text { Beobach- } \\
\text { tung }\end{array}$ & $\begin{array}{l}\text { PSA } \\
\text { alle } 4 \text { Jahre }\end{array}$ & 162.243 & 4,8 vs 8,2 & $\begin{array}{l}0,80 \\
p=0,04\end{array}$ & n.s. \\
\hline $\begin{array}{l}\text { Hugusson, } \\
2010\end{array}$ & Göteborg & $\begin{array}{l}\text { männlich, } \\
\text { 50-64 } \\
\text { Jahre }\end{array}$ & $\begin{array}{l}\text { Beobach- } \\
\text { tung }\end{array}$ & $\begin{array}{l}\text { PSA } \\
\text { alle } 2 \text { Jahre }\end{array}$ & 20.000 & $\begin{array}{l}8,2 \text { vs } 12,7 \\
p<0,0001\end{array}$ & $\begin{array}{l}0,56 \\
p=0,002\end{array}$ & n.s. \\
\hline $\begin{array}{l}\text { Sandblom, } \\
2011\end{array}$ & Norrkoping & $\begin{array}{l}\text { männlich, } \\
\text { 50-69 } \\
\text { Jahre }\end{array}$ & $\begin{array}{l}\text { Beobach- } \\
\text { tung }\end{array}$ & $\begin{array}{l}\text { DRU + PSA } \\
\text { alle } 3 \text { Jahre }\end{array}$ & 1.494 & 3,9 vs 5,7 & n.s. & \\
\hline
\end{tabular}

Abb. 5. Früherkennung des Prostatakarzinoms mithilfe der PSA-Bestimmung.

Abb. 6. Früherkennung des Lungenkarzinoms mithilfe der Low-Dose-CT (LDCT) im Vergleich zum Röntgen des Thorax und Beobachtung.

\begin{tabular}{|c|c|c|c|c|c|c|c|}
\hline $\begin{array}{l}\text { Studie, Erst- } \\
\text { autor, Jahr }\end{array}$ & Risikogruppe & Kontrolle & \begin{tabular}{|l} 
Neue \\
Methode
\end{tabular} & $\mathrm{N}$ & $\begin{array}{l}\text { Lungen- } \\
\text { karzinom }\end{array}$ & $\begin{array}{l}\text { LK- } \\
\text { Mortalität }\end{array}$ & \begin{tabular}{|l} 
ÜL \\
(HR)
\end{tabular} \\
\hline $\begin{array}{l}\text { LSS } \\
\text { Gohagan, } \\
2005\end{array}$ & $\begin{array}{l}\text { 55-74 Jahre, } \\
>30 \\
\text { Packungsjahre }\end{array}$ & $\begin{array}{l}\text { Röntgen } \\
\text { Thorax }\end{array}$ & LDCT & 3.318 & 20 vs 40 & n. u. & n. u. \\
\hline $\begin{array}{l}\text { DANTE } \\
\text { Infante, } 2009\end{array}$ & $\begin{array}{l}\text { männlich, } \\
60-75 \text { Jahre, } \\
\text { >20 Packungs- } \\
\text { jahre }\end{array}$ & Beobachtung & LDCT & 2.472 & $\begin{array}{l}34 \text { vs } 60 \\
p=0,016\end{array}$ & n. s. & n. s. \\
\hline $\begin{array}{l}\text { DLCST, } \\
\text { Saghir, } 2012\end{array}$ & $\begin{array}{l}\text { 50-70 Jahre, } \\
>20 \text { Packungs- } \\
\text { jahre }\end{array}$ & Beobachtung & LDCT & 4.104 & $\begin{array}{l}24 \text { vs } 69 \\
p<0,001\end{array}$ & n. s. & n. s. \\
\hline $\begin{array}{l}\text { NSLT, 2011, } \\
2013\end{array}$ & $\begin{array}{l}\text { 55-74 Jahre, } \\
>30 \text { Packungs- } \\
\text { jahre }\end{array}$ & $\begin{array}{l}\text { Röntgen } \\
\text { Thorax }\end{array}$ & LDCT & 53.454 & $\begin{array}{l}572 \text { vs } 645 \\
1,13 \\
(1,03-1,23)\end{array}$ & $\begin{array}{l}309 \text { vs } 247 \\
0,80 \\
(0,73-0,93)\end{array}$ & $\begin{array}{l}2000 \text { vs } \\
1877 \\
0,93 \\
(0,86-0,99)\end{array}$ \\
\hline
\end{tabular}

n. s. = nicht signifikant $\quad$ n. u. $=$ nicht untersucht europäischen Studien [23, 24] signifikante Vorteile zugunsten eines PSA-Screenings im Abstand von 2-4 Jahren nachgewiesen wurden. Dies hatte zur Folge, dass das PSA-Screening als Früherkennungsmaßnahme nach evidenzbasierten Kriterien nicht anerkannt ist, es aber dennoch häufig angeboten wird.

Hautkrebs: Früherkennung ohne obere Altersbegrenzung - und ohne Nutzen?

Melanome gehören zu den häufigsten Krebserkrankungen bei jungen Erwachsenen. Im fortgeschrittenen Stadien ist die Heilungschance gering. Um maligne Melanome zu verhindern, ist die Vermeidung erhöhter UV-Bestrahlung und Schutz vor Sonnenbränden wirksam. Zur Früherkennung wird die visuelle Untersuchung der gesamten Haut zur Erkennung von Melanomen in situ und invasiver Melanome empfohlen, dies in 2-jährlichen Abständen ab dem Alter von 35 Jahren, ohne obere Altersbegrenzung. Im Vorfeld der bundesweiten Einführung des gesetzlichen Hautkrebsscreenings (2008) hatte ein in Schleswig-Holstein durchgeführtes Projekt der Jahre 2003-2004 unter Teilnahme von knapp 370000 Menschen gezeigt, dass die melanomassoziierte Mortalität durch das Hautscreening um etwa die Hälfte gesenkt werden konnte [26, 27]. Allerdings stieg die Melanominzidenz nach Abschluss des Projektes wieder an und liegt seit 2008 auf Bundesniveau. Auch aus anderen Ländern gibt es bisher keine Studien zur Senkung der ma- lignombedingten Mortalitätsrate. Aufgrund der wenig überzeugenden Datenlage wird ein Hautkrebsscreening außerhalb Deutschlands nicht durchgeführt.

Lungenkarzinom: Früherkennung bei Hochrisikopersonen?

Zur Primärprävention von Lungenkrebs gehören der Nikotinverzicht und die Vermeidung einer Exposition gegenüber kanzerogenen Schadstoffen. Im Bereich der Früherkennung sind die früher eingesetzten Methoden der konventionellen Röntgenuntersuchung des Thorax und der zytologischen Untersuchung des Sputums nicht effektiv [28]. Die Low-Dose-Computertomografie (LDCT) ist sensitiver [29]. Frühe, kleine Studien hatten im Vergleich zur reinen Beobachtungsstrategie mehr Lungenkarzinome erkannt, jedoch keinen signifikanten Einfluss auf die lungenkrebsbedingte Mortalität und die Gesamtmortalität erbracht [30, 31] (Abb. 6). Erst der große National Lung Screening Trial (NLST) zeigte eine Überlegenheit der Low-Dose-CT gegenüber dem Röntgen des Thorax in der Früherkennung und senkte sowohl die Sterblichkeit aufgrund von Lungenkrebs $(-20 \%)$ als auch die Gesamtmortalität (-7\%) [32]. Das Problem der Low-Dose-CT ist die geringe Spezifität; so wurden in der Studie des NLST-Teams im CT 3-mal häufiger Raumforderungen diagnostiziert als durch die Röntgenaufnahmen. Eine Früherkennung unter Einbeziehung der CT muss deshalb hohen Qualitätsanforderungen genügen und sicherstellen, dass die CT-Aufnahmen von erfahrenen 
Abb. 7. Empfehlungen zur Krebsfrüherkennung auf europäischer Ebene [33].

\begin{tabular}{lll} 
Karzinom & Start & Ende \\
\hline Kolorektal & $50-60$ & $70-75$ \\
\hline Mamma & 50 (nicht vor 40) & $70-75$ \\
\hline Zervix & $25-30$ & $60-65$ \\
\hline
\end{tabular}

Ärzten befundet werden. In den USA wurde bereits ein entsprechendes Früherkennungsprogramm etabliert. Es wendet sich an Personen im Alter zwischen 55 und 80 Jahren, die in den zurückliegenden 15 Jahren geraucht haben und einen Nikotinkonsum von mindestens 30 Pack Years (z.B. 1 Packung Zigaretten pro Tag über 30 Jahre) vorweisen. Ein solches Screeningprogramm ist zwar aufwändig, dafür ist der zu screenende Personenkreis eng begrenzt. Über die Durchführbarkeit in Deutschland sollte diskutiert werden.

\section{CLL und multiples Myelom: Potenzielle}

\section{Früherkennungskandidaten}

Während das Programm zur Früherkennung von Zervixkarzinomen gut etabliert ist und mit der regelmäßigen Testung auf humane Papillomaviren (HPV) auch sinnvolle Erweiterungen erfahren hat, sind andere Krebserkrankungen bisher bei der Früherkennung außen vor geblieben. Dies betrifft unter anderem die CLL, die sich in der Regel langsam über eine Vorstufe (monoklonale BLymphozytose) entwickelt und deshalb prinzipiell gut für Maßnahmen der Früherkennung infrage kommt. Das gilt in ähnlicher Weise für das Multiple Myelom (MM), das sich aus einer monoklonalen Gammopathie über verschiedene Stadien hinweg zu höherer Malignität entwickeln kann. Das Problem ist bei beiden Erkrankungen, dass sich innerhalb 1 Jahres bei nur etwa 1 von 100 Betroffenen aus einer Vorstufe tatsächlich ein aggressiv wachsender, therapiebedürftiger Tumor entwickelt. Ein Nutzen wird sich erst dann ergeben können, wenn die Therapie von CLL und MM in frühen Stadien effektiver wird oder bei früher Diagnose die Lebensqualität besser erhalten werden kann.

\section{Restriktive Empfehlungen aus Europa}

Mit dem European Code against Cancer liegen Empfehlungen für die Krebsfrüherkennung vor, die im Vergleich zum bisherigen Vorgehen in Deutschland eher restriktiv sind [33]. Beginn und Dauer der Früherkennungsmaßnahmen sind durchweg begrenzt (Abb. 7). Die Ausweitung der Früherkennung auf weitere Entitäten ist derzeit nicht vorgesehen. Während die Evidenz in Bezug auf das Lungenkarzinom vorhanden ist, ist sie bei anderen Tumorlokalisationen (Prostata, Haut, Niere, Ovar, Schilddrüse, MM und CLL) nicht oder nur begrenzt vorhanden.

\section{Besonderheiten der Therapie älterer Patienten mit chronisch lymphatischer Leukämie (CLL)}

\section{Referent: Michael Hallek, Köln}

Die CLL ist eine Erkrankung des älteren Menschen mit einem medianen Alter von 72 Jahren bei Diagnosestellung [34]. Viele
CLL-Patienten haben zusätzliche Erkrankungen (Komorbiditäten), deren Häufigkeit ab einem Alter von etwa 55 Jahren zunimmt [2]. Bei über 75-jährigen CLL-Patienten (43\% der CLL-Patienten) werden durchschnittlich 4,2 zusätzliche Erkrankungen festgestellt [35]. Es handelt sich dabei vor allem um kardiovaskuläre Erkrankungen, Diabetes, Lungenerkrankungen und Zweitmalignome [36]. Nur $11 \%$ der CLL-Patienten sind frei von relevanten Komorbiditäten [36]. Trotz des hohes Erstdiagnosealters ist die Gruppe der alten Patienten ( $\geq 75$ Jahre) in kontrollierten Therapiestudien deutlich unterrepräsentiert. Über 75 Jahre alte Patienten sind in den Studien der Deutschen CLL-Studiengruppe (DCLLSG) nur zu etwa $3 \%$ erfasst. Doch obwohl die modernen Therapiekonzepte überwiegend bei jüngeren Patienten evaluiert worden sind, scheinen davon auch die älteren Patienten zu profitieren, wie dänische Registerdaten zeigen [37].

Da sich das chronologische und das biologische Alter eines Menschen beträchtlich unterscheiden kann, wird in den Studien der DCLLSG vor Beginn einer Therapie ein geriatrisches Assessment vorgenommen, etwa mit Einordnung der Patienten in «go go», «slow go» und «no go» bezüglich ihrer Therapiefähigkeit [38, 39]. Ein umfassendes geriatrisches Assessment wäre für diesen Zweck allerdings in der Praxis zu zeitaufwändig. Es wurden daher möglichst einfache Instrumente für die Bestimmung der Effekte der Komorbidität in den Studien verwendet wie der «Cumulative Illness Rating Scale - Geriatric» (CIRS-G) [40]. Mithilfe des CIRS-G wird die Komorbidität der wichtigsten Organsysteme nach dem Schweregrad mit 0 bis 4 bewertet und die Punkte anschließend summiert. Der Zeitaufwand beträgt ca. 5 min. Bei Anwendung des CIRS-G in GCLLSG-Studien bildet sich das bekannte Spektrum an führenden Begleiterkrankungen ab wie Bluthochdruck, Hyperlipidämie/Adipositas und Diabetes mellitus. Auch der Anstieg der Komorbidität mit zunehmenden Alter lässt sich gut abbilden. Dennoch lässt sich der Einfluss der Komorbidität auf die Prognose des Patienten in den Studien nicht ganz so einfach festmachen, da die Komorbidität eng mit anderen Einflussfaktoren (z.B. reduzierte Therapieintensität) verknüpft ist. Dennoch nimmt der Therapieerfolg gemessen am Gesamtüberleben ab, wenn CLL-Patienten zwei und mehr Begleiterkrankungen aufweisen oder wenn der CIRS-Punktwert über 6 liegt.

\section{Therapiestrategien bei «fitten» Patienten}

Patienten mit einem CIRS-G-Wert von bis zu 6 Punkten gelten in den Studien der DCLLSG als fit («go go»). In der CLL8-Studie wurden Patienten mit nicht vorbehandelter, aktiver CLL, einem CIRS-G Score $\leq 6$ und einer Kreatinin-Clearance $\geq 70 \mathrm{ml} / \mathrm{min}$ eingeschlossen und erhielten eine Chemotherapie mit Fludarabin und Cyclophosphamid entweder mit oder ohne Rituximab (FCR vs. FC) [41]. Die antikörperhaltige Therapie (Chemoimmuntherapie) konnte das Gesamtüberleben verlängern (Abb. 8). Allerdings nahmen bei den älteren Patienten ( $\geq 70$ Jahre) die Neutropenien und Infektionen in der Chemotherapiegruppe signifikant $\mathrm{zu}$, bei der Chemoimmuntherapie war der Einfluss des Lebensalters auf die Verträglichkeit etwas weniger deutlich.

Werden CLL-Patienten ungeachtet ihrer Fitness chemoimmuntherapeutisch behandelt [42], so ist bei $\geq 70$-Jährigen ein kürzeres 
Abb. 8. Überlebensvorteil durch antikörperhaltige Therapie. FC = Fludarabin/Cyclophosphamid, FCR = Fludarabin/Cyclophosphamid/Rituximab; modifiziert nach [41].

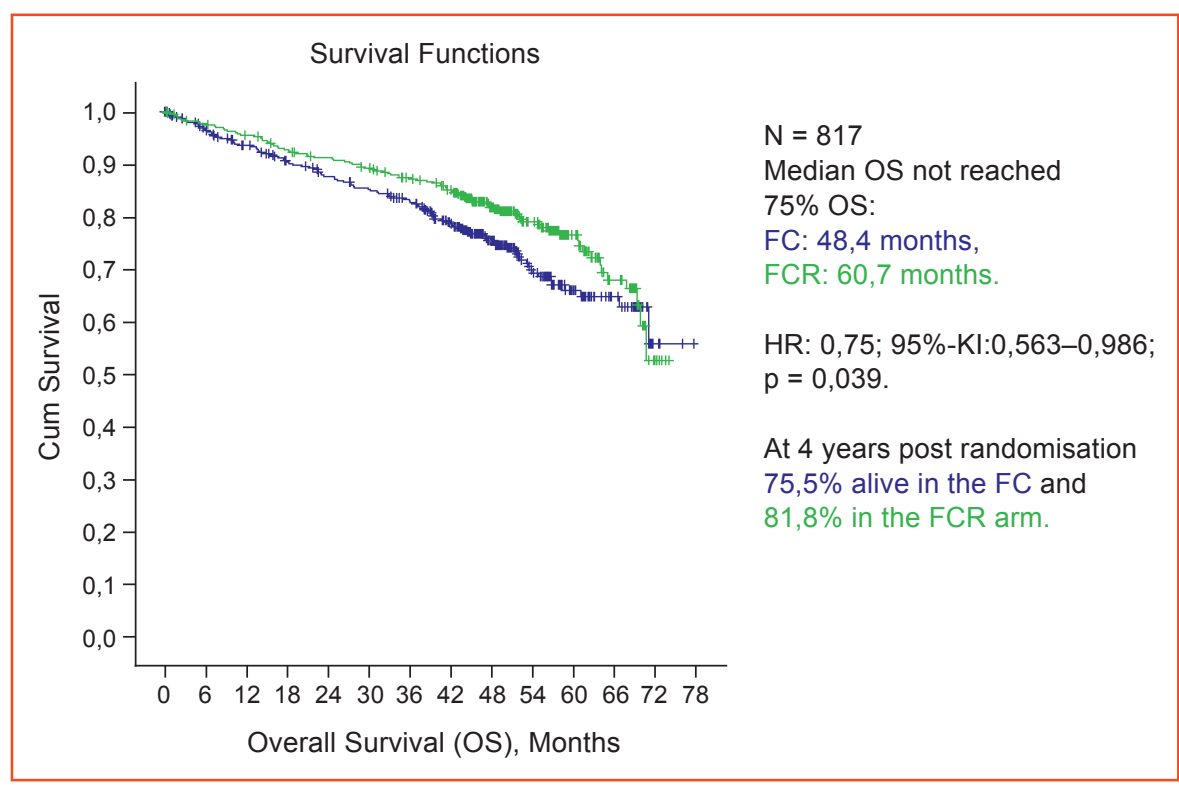

Gesamtüberleben unter der Chemoimmuntherapie mit FCR sowie einen deutlicher Anstieg an therapieassoziierten Zytopenien und Infektionen zu beobachten. Typische Komplikationen bei älteren Patienten mit FCR-Therapie sind unter anderem Myelosuppressionen, eine höhere Infektionsrate [43], sowie frühe Therapieabbrüche $[44,45]$.

\section{Was tun bei relevanter Komorbidität?}

Da Patienten mit relevanter Komorbidität eine stark belastende Therapie nicht zugemutet werden kann, stellt sich die Frage nach den Therapiealternativen. Dieses Problem wurde im Rahmen randomisierter, kontrollierter Studien der GCLLSG systematisch untersucht. In diesen Studien wurden CLL-Patienten risiko-, stadien- und altersadaptiert behandelt. Es zeigt sich, dass über 65 Jahre alte Patienten genauso von einer Erstlinienherapie mit Chlorambucil (CLB) profitierten wie mit dem deutlich effizienteren Fludarabin: das mediane Gesamtüberleben lag für CLB bei 63,6 Monaten im Vergleich zu 45,8 Monaten mit Fludarabin (Unterschied nicht signifikant) [46]. Todesfälle waren vorwiegend auf die Grunderkrankung zurückzuführen und nur zu einem geringen Teil mit der Nebenwirkungen der Therapie assoziiert (10\% der Todesfälle in der Fludarabin-Gruppe und 3\% der Todesfälle in der CLB-Gruppe). Auch in einer weiteren Studie war CLB bei älteren CLL-Patienten den moderneren Therapien mit Fludarabin oder Fludarabin/Cyclophosphamid nicht unterlegen [47]. Die nachfolgenden von der GCLLSG initiierten Studien untersuchten deshalb fortan fitte («go go») und nicht fitte («slow go») Patienten in unterschiedlichen Therapiestudien. So wurde in der dreiarmigen CLL11-Studie bei Patienten der «Slow go»-Kategorie CLB allein mit CLB-Rituximab und gegen CLB-Obinutuzumab verglichen. Der Antikörper Obinutuzumab (OBI) wurde durch Proteinengineering so modifiziert, dass seine Wirkung gegen B-Zellen im Vergleich zu Rituximab deutlich stärker ist $[48,49]$. Die Studienteilnehmer des CLL11-Protokolls hatten ein aktive, nicht vorbehandelte CLL mit Komorbiditäten bei einem CIRS-Score $>6$ und/ oder einer Kreatinin-Clearance von $<70 \mathrm{ml} / \mathrm{min}$ [50]. Mit beiden antikörperhaltigen Therapien konnten deutlich mehr Remissionen erreicht werden als mit CLB allein. In der CLB/OBI-behandelten Gruppe war die Remissionsrate mit 77\% (davon 22\% komplette Remissionen) am höchsten. Diese Patienten erreichten auch das längste Gesamtüberleben, das nach 5 Jahren um fast $10 \%$ besser war als in der Rituximab-Gruppe (66\% vs. 57\%) [51]. Offenbar kann durch die Kombination einer wenig aggressiven Chemotherapie mit einem potenten Antikörper wie OBI die Überlebenszeit deutlich verlängert werden.

\section{Neue Substanzen könnten auch älteren Patienten helfen}

Für die CLL-Therapie sind vor kurzem eine Reihe spezifisch wirkender Substanzen wie Ibrutinib, Idelalisib und Venetoclax zugelassen worden. In der RESONATE-2-Studie wurde Ibrutinib gegen CLB bei älteren Patienten ( $\geq 65$ Jahre) getestet und ein deutlicher Vorteil im progressionsfreien Überleben und im Gesamtüberleben für den Bruton-Tyrosinkinase-Inhibitor gezeigt [52]. Bei älteren Patienten mit einem CLL-Rezidiv wurde durch die Kombination von Idelalisib und Rituximab ein verlängertes Gesamtüberleben im Vergleich zur Behandlung mit Rituximab (plus Placebo) erreicht [53, 54]. Derzeit wird im Rahmen der CLL14-Studie bei «Slow go»-Patienten eine neue Kombination - nämlich der Bcl2Antagonist Venetoclax plus OBI - gegen den Standard CLB/OBI untersucht. Die Therapie mit Venetoclax plus OBI führte zu einer raschen Elimination der B-Zellen aus dem peripheren Blut und unterdrückte die Krankheit bei den meisten Patienten auch über einen längeren Zeitraum (kein Nachweis einer minimalen Resterkrankung bei $91 \%$ der Patienten nach 15 Monaten). Ob sich daraus ein Überlebensvorteil ableiten lässt, ist vorerst noch offen und wird weiter untersucht.

\section{Behandlungsalgorithmus der CLL im Jahr 2018}

Die aktuellen Behandlungskonzepte orientieren sich nach wie vor an der Fitness der Patienten: Fitte Patienten ohne genetische 


\begin{tabular}{llll}
\hline \multirow{2}{*}{ Stage } & Fitness & $\begin{array}{l}\text { del(17p) } \\
\text { p53mut }\end{array}$ & Therapy \\
\hline Binet A-B, Rai 0-II, inactive & Irrelevant & Irrelevant & None \\
\hline & \multirow{2}{*}{ Go go } & No & FCR (BR above 65 years?) \\
\cline { 2 - 4 } $\begin{array}{l}\text { Active disease or Binet C } \\
\text { or Rai III-IV }\end{array}$ & Yes & $\begin{array}{l}\text { Ibrutinib, Idelalisib+Rituximab } \\
\text { (Allogeneic SCT) }\end{array}$ \\
\cline { 2 - 4 } & Slow go & No & $\begin{array}{l}\text { Chlorambucil + Obinutuzumab } \\
\text { (GA-101) or Ibrutinib }\end{array}$ \\
\cline { 2 - 4 } & & Yes & $\begin{array}{l}\text { Ibrutinib, Alemtuzumab, HD } \\
\text { Rituximab or Ofatumumab }\end{array}$ \\
\hline
\end{tabular}

Abb. 9. Erstlinientherapie der CLL.

Die pharmakogenetische Diagnostik unter dem Aspekt des Alters

Die pharmakogenetische Diagnostik vor Beginn einer Erstlinientherapie des KRK ermöglicht eine Vorhersage der zu erwartenden Toxizität. Die regelhafte Bestimmung der UDP-Glucuronosyltransferase (UGT1A1) vor Beginn einer palliativen Chemotherapie mit Irinotecan wird nicht empfohlen [17], da sich daraus bisher keine konkreten, in Algorithmen fassbaren, therapeutischen Konsequenzen ableiten lassen. Gerade bei älteren Patienten ist aber die genaue Erfassung des Bilirubinwerts im Serum wichtig, um gegebenenfalls einen Morbus Meulengracht oder andere BilirubinKonjugationsstörungen frühzeitig zu erfassen.

Die Bestimmung des Dihydropyrimidin-Dehydrogenase(DPD)Mangels ist eine diagnostische Option vor Beginn einer Fluoropyrimidin-Therapie. Die regelhafte Evaluation des DPYD^2A-Polymorphismus kann durchgeführt werden [17] und wird an unserem Zentrum regelhaft bei allen Patienten im Alter ab 70 Jahren vorgenommen. Ein DPD-Mangel betrifft etwa 1-3\% der Patienten und kann insbesondere bei Vorliegen von Komorbiditäten die mit einer Chemotherapie verbundenen Risiken erhöhen.

\section{Besonderheiten der medikamentösen Therapie im Alter}

In Bezug auf die adjuvante Therapie findet sich in der S3-Leitlinie für das KRK eine klare Empfehlung, wonach bei Patienten im Alter von über 70 Jahren keine Oxaliplatin-haltige Therapie erfolgen sollte [17], da bei älteren Patienten darunter vermehrt Nebenwirkungen beobachtet wurden. Zur Wirksamkeit der adjuvanten Therapie bei älteren Patienten liegen widersprüchliche Studienergebnisse vor (Abb. 10) [57-59]. Letztlich haben insbesondere die Ergebnisse der Studien MOSAIC [57] und National Surgical Adjuvant Breast and Bowel Project (NSABP) C-07 [58] dazu geführt, Oxaliplatin-haltige Therapien bei Älteren kritisch zu bewerten. Beide Studien konnten bei älteren Patienten durch die Hinzunahme von Oxaliplatin zu einer Fluoropyrimidin-Therapie keinen Überlebensvorteil belegen.

In der Onkopedia-Leitlinie Kolonkarzinom [55] werden für die Therapiefindung auch die Kriterien «biologisches Alter» und «Komorbidität» bei Patienten mit Kolonkarzinom im Stadium III herangezogen (Abb. 11). Daran wird unter anderem festgemacht, ob die Patienten ein Fluoropyrimidin plus Oxaliplatin erhalten können (in der Regel bei einem chronologischen Alter von $\leq 70$ Jahre) oder ob - bei älteren Patienten - eine Monotherapie mit einem Fluoropyrimidin, vorzugsweise Capecitabin, erfolgt. 


\section{Vorgehen bei Metastasierung}

Besteht die Indikation zu einer medikamentösen Tumortherapie, so soll diese entsprechend der aktuellen S3-Leitlinie zum Zeitpunkt des Nachweises der Metastasen unabhängig von einer möglichen Symptomatik unter Berücksichtigung möglicher Kontraindikationen eingeleitet werden. Alter per se stellt keine Kontraindikation dar [17]! Nicht geeignet für eine intensive Kombinationstherapie sind Patienten, deren Allgemeinzustand eine solche nicht zulässt oder die eine intensivierte Behandlung aufgrund der zu erwartenden Nebenwirkungen ablehnen. Bei der Beurteilung der Therapiefähigkeit steht explizit nicht das chronologische Alter im Vordergrund, sondern vielmehr die biologischen Rahmenbedingungen in Bezug auf den Patienten und die Tumorerkrankung.

Um die Wahl der optimalen Erstlinientherapie zu ermöglichen, können die Patienten definierten Behandlungsgruppen zuordnet

Abb. 10. Studien zur adjuvanten Therapie des KRK.
Adjuvante Therapie bei älteren Patienten

- MOSAIC-Studie

- Patienten 70-75 Jahre $(n=315)$

- FOLFOX4 vs FL

- OS: HR 1,10 (95\%-KI: 0,73-1,65)

- NSABP C-07 Studie

- Patienten > 69 Jahre $(n=396)$

- FLOX vs 5-FU Bolus

- OS, HR 1,18; 95\%-KI: 0,86-1,62;

$p=0,30)$

- Signifikante Interaktion Alter / Oxalipla-

tin: $p=0,0391$

- N016968 Studie

- XELOX versus FU/FA

- kein negativer Effekt des Alters auf das OS werden, in Abhängigkeit vom Allgemeinzustand (Tolerabilität einer intensiven Therapie), von der Krankheitsausdehnung inklusive Lokalisation und von der Molekularbiologie des Tumors [17].

Bei der Abschätzung der Therapiefähigkeit wird entsprechend dem in der S3-Leitlinie aufgeführten Therapiealgorithmus (Abb. 12) auf der ersten Ebene zwischen den für eine Chemotherapie geeigneten, bedingt geeigneten und nicht geeigneten Patienten unterschieden [17]. Gerade für ältere, bedingt therapiefähige Patienten steht mit einem Fluoropyrimidin plus Bevacizumab eine Kombination zur Verfügung, die laut S3-Leitlinie eine sinnvolle Behandlungsoption darstellt. Dort heißt es: «Studienergebnisse weisen darauf hin, dass die Erstlinienchemotherapie mit einem Fluoropyrimdin und Bevacizumab bei älteren Patienten und solchen, die für eine initiale Irinotecan-basierte Therapie nicht geeignet waren, effektiv ist ...» Hier ist vor allem die AVEXStudie zu nennen, die bei Patienten $\geq 70$ Jahren einen Vorteil im progressionsfreien Überleben bei Behandlung mit Capecitabin plus Bevacizumab versus einer Capecitabin-Monotherapie gezeigt hat [60]. Der Unterschied betrug 9,1 versus 5,6 Monate; damit profitierten die Älteren vergleichbar stark wie die Jüngeren von der Kombination. Auch das Gesamtüberleben der älteren Patienten konnte durch die Zugabe von Bevacizumab verlängert werden, der Effekt war jedoch (womöglich aufgrund der geringen Fallzahl von 140 älteren Patienten pro Behandlungsarm) nicht signifikant.

\section{Die chirurgische Therapie bei älteren KRK-Patienten}

Patienten mit KRK und einem Alter von über 80 Jahren, bei denen eine chirurgische Intervention erfolgte, wiesen in einer Fallauswertung des Universitätsklinikums Erlangen einige Besonder-
Abb. 11. Therapiestruktur beim Kolonkarzinom.

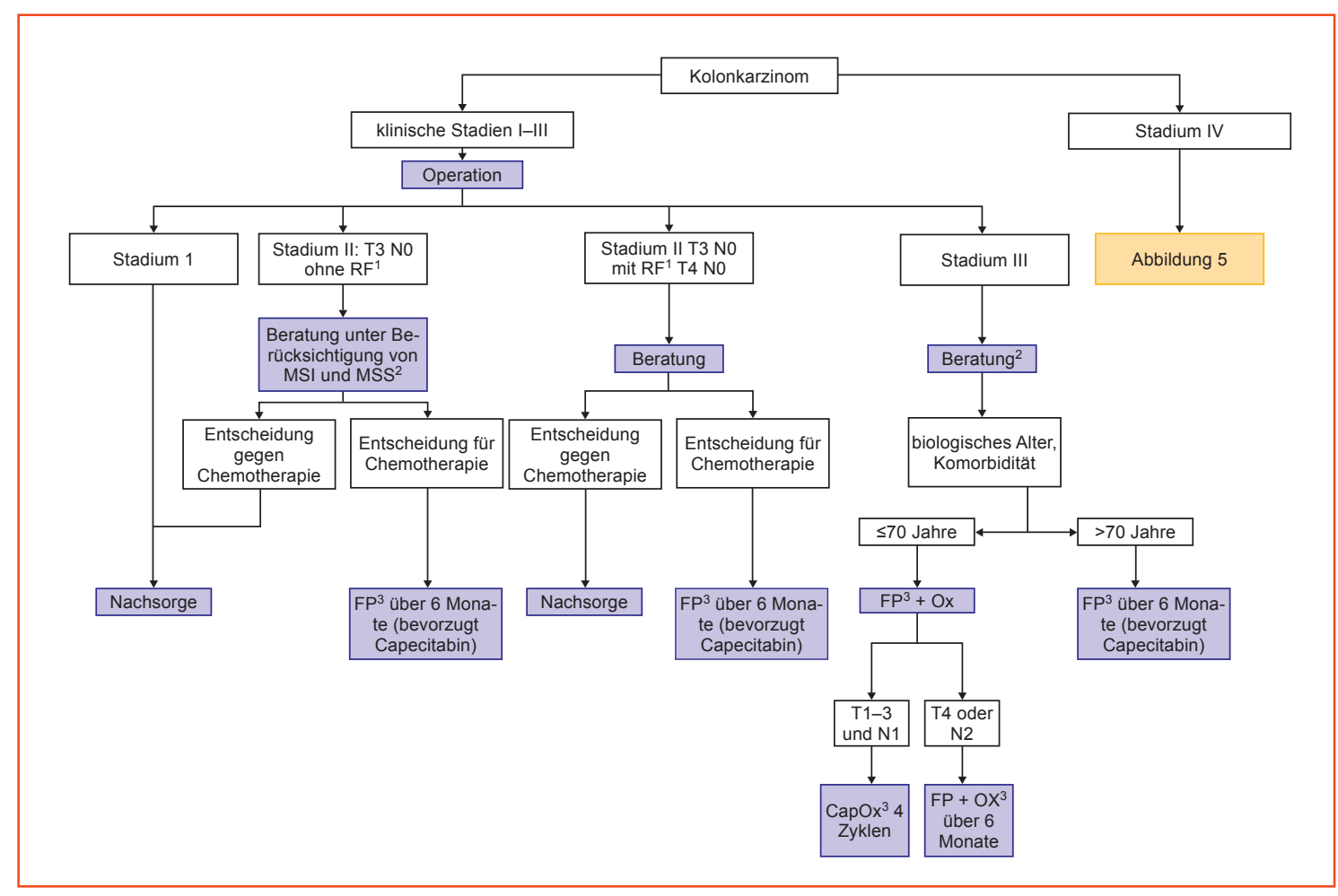


Abb. 12. Therapeutisches Vorgehen in der Erstlinientherapie bei metastasiertem KRK; nach [17].
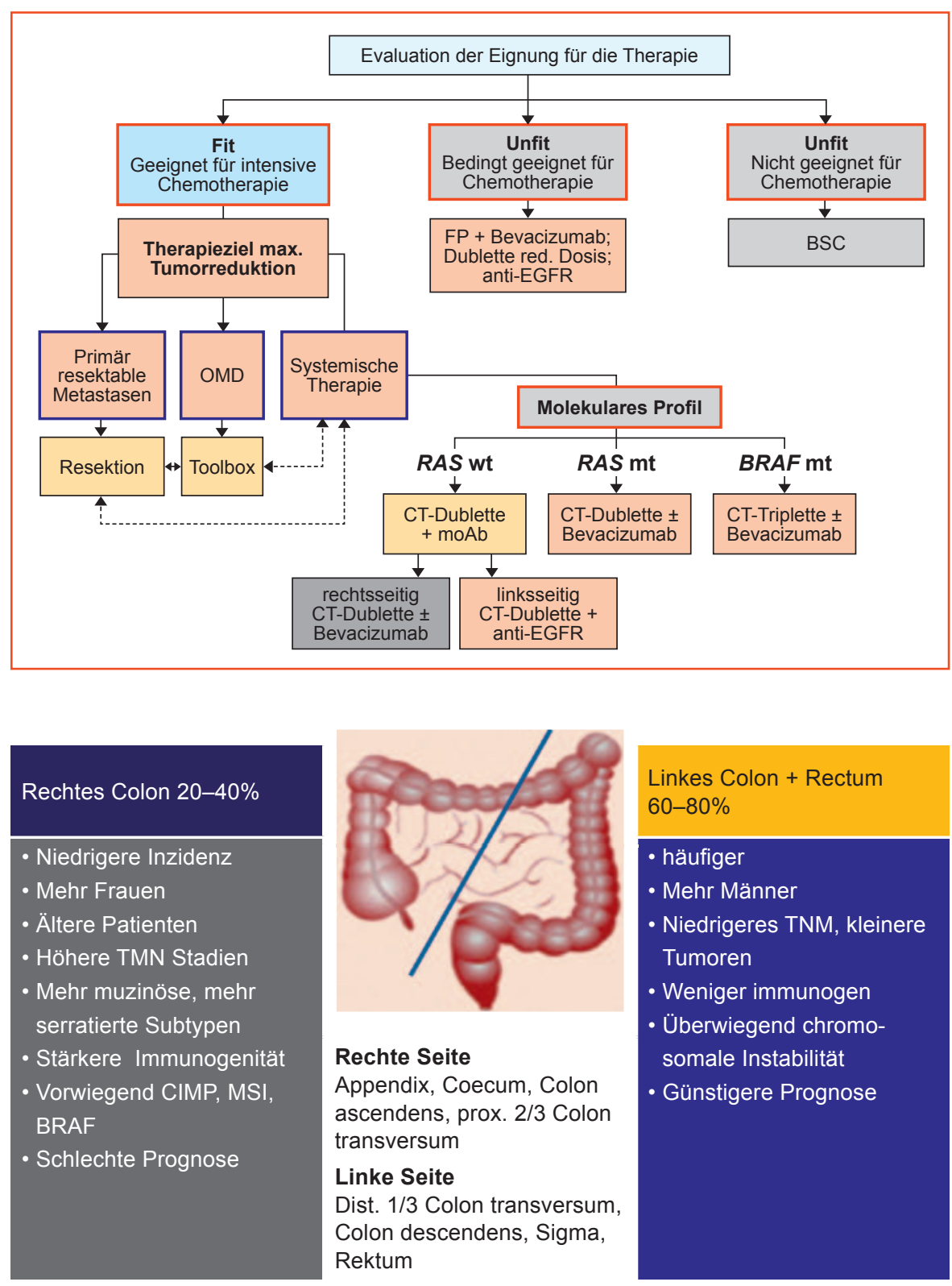

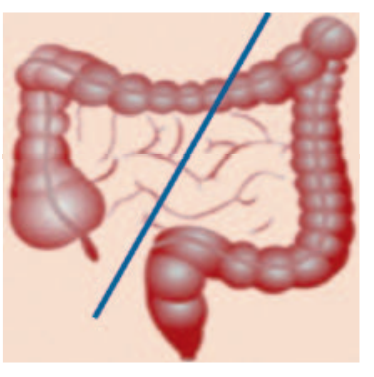

\section{Rechte Seite}

Appendix, Coecum, Colon ascendens, prox. $2 / 3$ Colon transversum

\section{Linke Seite}

Dist. $1 / 3$ Colon transversum Colon descendens, Sigma, Rektum

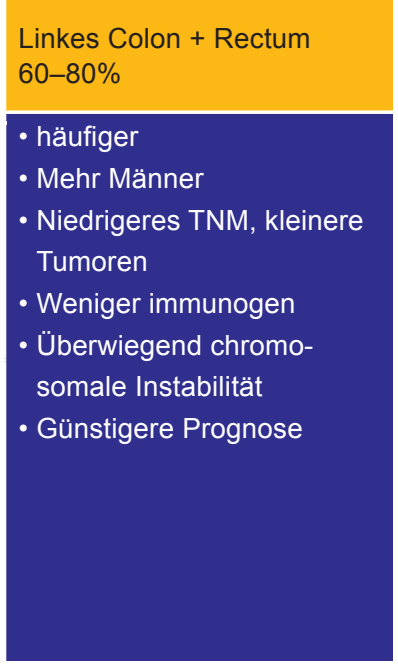

Abb. 13. Merkmale rechts- und
Tumoren im kolorektalen Bereich.

heiten auf: Es handelte sich überwiegend um weibliche Patienten, es lag eine höhere ASA-Klassifikation vor (ASA = American Society of Anesthesiologists), es waren mehr Notfalleingriffe nötig, es traten vermehrt schwere präoperative Komplikationen auf und es bestand eine erhöhte postoperative Morbidität und Mortalität.

Während die postoperative Morbidität älterer Patienten (>70 Jahre) nach Resektion von Lebermetastasen in der Metaanalyse von van Tuil et al. [61] allerdings nur wenig gegenüber den jüngeren Patienten erhöht war, stieg die postoperative Mortalität im höheren Alter wie zu erwarten an. Liegt der Cut-off-Wert bei 75 Jahren, ist sowohl die Morbidität als auch die Mortalität bei den Älteren im Vergleich zu den Jüngeren deutlich erhöht.

\section{Molekulare Tumorpathologie im höheren Lebensalter}

Im höheren Lebensalter treten gehäuft genetische Mutationen auf, die das Risiko für Krebs erhöhen. Im Alter sind folglich bösartige Tumoren zwar häufiger, ihr molekulares Profil unterscheidet sich jedoch nicht signifikant von den Tumoren jüngerer Menschen [62]. Bei älteren Patienten ist der Tumor allerdings häufiger als bei jüngeren im rechten Kolon lokalisiert, was mit einer ungünstigeren Prognose verbunden ist (Abb. 13). Neue Medikamente wie die Checkpoint-Inhibitoren, deren Wirksamkeit bei Mismatch Repair-Defizienz (MMRd) bzw. Mikrosatelliteninstabilität (MSI-h) gezeigt worden ist, könnten aufgrund der Charakteristika rechtsseitiger Tumoren auch für die Gruppe der älteren Patienten künftig von besonderer Bedeutung sein.

\section{Besonderheiten in der Nachsorge}

Im Rahmen der Krebsnachsorge werden beim KRK im UICCStadium II oder III (UICC = Union for International Cancer Control) regelmäßige Koloskopien und CT-Untersuchungen empfoh- 
len [17]. Der Nutzen dieser Maßnahmen ist für Patienten bis zum Alter von 87 Jahren belegt, sodass die Nachsorge keiner Altersbegrenzung unterliegt. Vielmehr sollte die Art und Dauer der Nachsorge durch das biologische Alter, die Operabilität (und den Willen des Patienten, im Falle eines Rezidivs eine Operation vornehmen zu lassen) sowie durch die Begleiterkrankungen bestimmt werden.

\section{Besonderheiten der Therapie älterer Patientinnen mit Mammakarzinom}

\section{Referentin: Diana Lüftner, Berlin}

Bei Frauen mit primärem Mammakarzinom ist - weitgehend unabhängig vom Lebensalter - die operative Tumorresektion die wichtigste Therapieoption. Die adjuvante Strahlentherapie verliert mit zunehmendem Alter an Bedeutung, wohingegen die adjuvante endokrine Therapie in der Regel auch im höheren Alter noch gut durchführbar ist. Gleiches gilt für Chemotherapien, insbesondere dann, wenn sie nicht Anthrazyklin-haltig sind. Der Grund, weshalb ältere Patientinnen dennoch ein kürzeres tumorspezifisches Überleben haben, ist wohl eher bei Therapieproblemen im Stadium der Metastasierung zu suchen. Hier sind es vor allem Nebenwirkungen wie Neuropathien und Diarrhöen (z.B. unter Lapatinib), die eine Dosisreduzierung der eingesetzten Medikamente erfordern und damit den Therapieerfolg infrage stellen.

\section{Die meisten Wirkstoffe lösen Neuropathien aus}

In den aktuellen Empfehlungen der Arbeitsgemeinschaft Gynäkologische Onkologie (AGO) sind für die Therapie von Frauen mit triple-negativem metastasierten Mammakarzinom $(\mathrm{mBC})$ unabhängig von einer möglichen BRCA1/2-Keimbahnmutation fast ausschließlich Wirkstoffe mit neurotoxischem Potenzial wie Carboplatin und nab-Paclitaxel (nab = nanoparticle albumin-bound) aufgeführt [63] (Abb. 14).

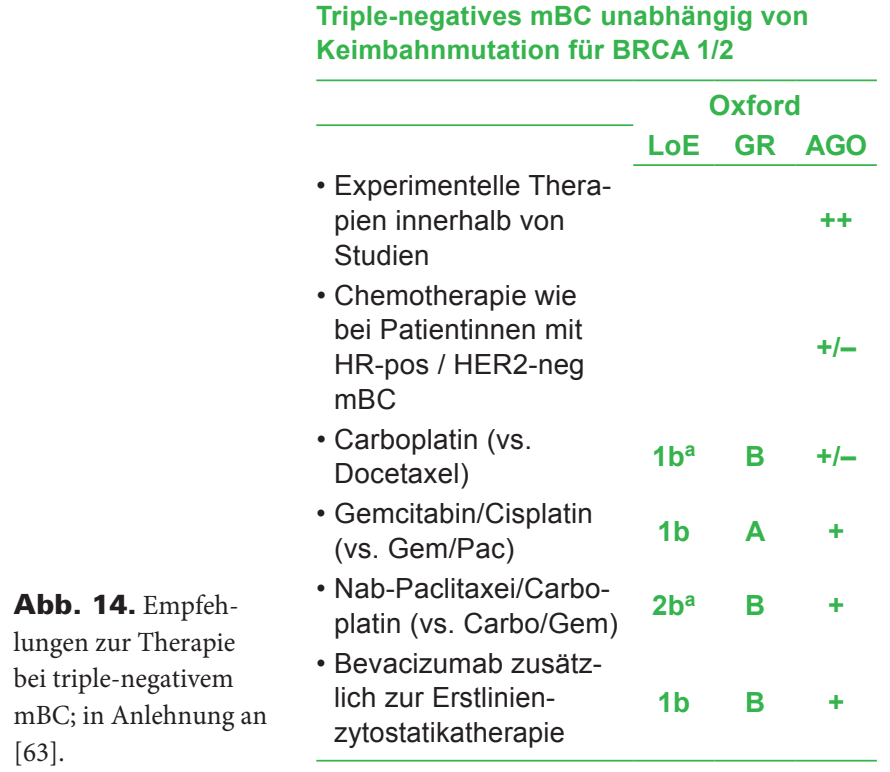

Da Patientinnen mit nur kurzem rezidivfreiem Intervall womöglich noch unter einer Neuropathie als Folge der adjuvanten Therapie leiden, ist ihnen eine erneute Therapie mit neurotoxisch wirkenden Substanzen kaum zuzumuten. Der Vorteil einer solchen Behandlung ist allerdings evident, so etwa gezeigt für nabPaclitaxel, mit dem in einer Studie zur Erstlinientherapie des mBC ein Gesamtüberleben von median 21 Monaten erreicht wurde [64]. Haben die Patientinnen dagegen schon mehrere Therapien in der metastasierten Situation absolviert, sind die Ansprechraten für mögliche Folgetherapien (Ixabepilon, Capecitabin, Eribulin) gering und deren Neurotoxizität ist relativ hoch. Demnächst könnten neue, noch in der Entwicklung befindliche Substanzen das Therapieangebot verbessern. Das gilt etwa für SacituzumabGovitecan, ein Antikörperkonjugat. Es wendet sich gegen das von Tumorzellen exprimierte Antigen Trop-2 und ist zusätzlich mit einem Topoisomerase-Inhibitor gekoppelt [65]. Mit einer objektiven Ansprechrate von 34\% wurden mit diesem Antikörper gute Resultate bei mehrfach vorbehandelten Patientinnen mit triplenegativem $\mathrm{mBC}$ erzielt, ohne dass dadurch vermehrt Neuropathien induziert wurden [65]. Das Ziel ist, mit nicht neurotoxischen Substanzen die Therapiesequenz effektiver und vor allem verträglicher zu gestalten.

\section{Therapien bei $m B C$ mit Keimbahnmutation}

Für Patientinnen mit mBC und nachgewiesener Keimbahnmutation für $B R C A 1 / 2$ steht mit Olaparib ein wirksamer, von der AGO empfohlener Poly(ADP-Ribose)-Polymerase(PARP)-Inhibitor zur Verfügung [63] (Abb. 15). Auch ältere Patientinnen mit Brustkrebs sollten auf das Vorliegen einer Keimbahnmutation getestet werden, falls bei ihnen besondere Risikokonstellationen vorliegen (Abb. 16). Zu beachten ist der Hinweis, dass möglichst alle Mutationsträgerinnen zu erfassen sind (Abb. 16) und somit die Indikation für eine Testung großzügig zu stellen ist. In Deutschland werden die Kosten für eine BRCA1/2-Testung allerdings nur bis zum Alter von 50 Jahren von den gesetzlichen Kassen übernommen, in den USA gilt diese Altersgrenze nicht. Zwar sind Erstdiagnosen eines Mammakarzinoms mit positivem BRCA1/2-Mutationsnachweis im höheren Alter selten, dies kann aber zum Teil mit der geringen Zahl der Testungen bei älteren Patientinnen zusammenhängen. So wurde von Kuchenbaecker et al. [66] gezeigt, dass

Abb. 15. Empfehlungen zur Therapie bei $\mathrm{mBC}$ und Keimbahnmutation; in Anlehnung an [63].
mBC mit Keimbahnmutation für BRCA 1/2

\begin{tabular}{|c|c|c|c|}
\hline & \multicolumn{3}{|c|}{ Oxford } \\
\hline & LoE & GR & AGO \\
\hline $\begin{array}{l}\text { - Experimentelle } \\
\text { Therapien innerhalb } \\
\text { von Studien }\end{array}$ & & & ++ \\
\hline $\begin{array}{l}\text { - Carboplatin } \\
\text { (vs. Docetaxel) } \\
\text { (wenn Platin-naiv) }\end{array}$ & $1 b^{a}$ & B & + \\
\hline - PARP-Inhibitoren & & & \\
\hline $\begin{array}{l}\text { - Olaparib } \\
\text { (HER2-negativ) }\end{array}$ & $1 b$ & B & + \\
\hline $\begin{array}{l}\text { - Olaparib } \\
\text { (HER2-positiv) }\end{array}$ & 5 & D & $+1-$ \\
\hline
\end{tabular}


Wer sollte auf Mutationen in den Genen BRCA1/2 und ggf. weiteren Risikogenen getestet werden?

\section{Oxford LOE: 2b GR: B AGO: ++}

Familien mit (je aus einer Familienseite) ${ }^{*}$

- mindestens 3 an Brustkrebs erkrankten Frauen unabhängig vom Alter

- mindestens 2 an Brustkrebs erkrankten Frauen, von denen eine vor dem 51. Lebensjahr

(LJ) erkrankt ist

- mindestens einer Brust- und einer an Eierstockkrebs erkrankten Frau

- mindestens einer an Brust- und Eierstockkrebs erkrankten Frau

- mindestens 2 an Eierstockkrebs erkrankten Frauen

- mindestens einer an beidseitigem Brustkrebs erkrankten Frau mit einem Erkrankungsalter vor dem 51. LJ

- mindestens eine an Brustkrebs erkrankte Frau vor dem 36. LJ

- mindestens ein an Brustkrebs erkrankter Mann und mindestens ein/e weitere/r Erkrankte/r an Brust- oder Eierstockkrebs

- empfohlene Kriterien mit einer Mutationsnachweisrate $<10 \%$ im höheren Lebensalter - eigene Erkrankung mit triple-negativem Mammakarzinom mit Erkrankungsalter $\leq 60$ Jahren

- eigene Erkrankung mit Ovarialkarzinom

- bei therapeutischer Relevanz (e.g. PARPi)

Abb. 16. Empfehlungen zur Mutationstestung; in Anlehnung an [63].
*Einschlusskriterien (EK) des deutschen Konsortiums für Familiären-Brust- und Eierstockkrebs (DK-FBEK) basierend auf der genetischen Analyse von 21401 Familien; bei Vorliegen eines dieser EK die Wahrscheinlichkeit für den Nachweis einer BRCA1/2-Mutation bei $\geq 10 \%$.

Eine Erfassung möglichst aller Mutationsträgerinnen ist anzustreben. Hierzu sollten geeignete Einschlusskriterien weiter validiert werden und Nutzen und Schaden in Studien erarbeitet werden.
Mutationsträgerinnen ein bis ins Alter hineinreichendes erhöhtes kumulatives Brustkrebsrisiko haben.

Der Vorteil im progressionsfreien Überleben für Olaparib wurde in der OlympiAD-Studie gezeigt [67]. Im Rahmen dieser Studie erhielten Patientinnen mit vorbehandeltem $\mathrm{mBC}$ und $B R C A 1 / 2$-Mutation entweder Olaparib oder eine frei wählbare Chemotherapie (Capecitabin, Eribulin, Vinorelbin). In der Gesamtgruppe der Patientinnen konnte mit Olaparib versus Chemotherapie das mediane progressionsfreie Überleben um etwa 3 Monate verlängert werden (7,0 vs. 4,2 Monate). Mit einer Hazard Ratio von 0,43 fiel bei den Patientinnen mit triple-negativem mBC der Vorteil zugunsten von Olaparib besonders deutlich aus, dagegen schien die Gruppe der Hormonrezeptor-positiven Patientinnen nicht besonders zu profitieren. Letzteres war in der EMBRACA-Studie unter Verwendung des PARP-Inhibitors Talazoparib nicht der Fall [68]. Diese Studie rekrutierte ebenfalls Patientinnen mit $\mathrm{mBC}$ und Keimbahnmutation, die auf Talazoparib oder einen Chemotherapie-Arm randomisiert wurden. Das mediane Alter der Studienteilnehmerinnen betrug 45 bzw. 50 Jahre mit einem Anteil an Patientinnen über 50 Jahre von 37\% (TalazoparibArm) bzw. 54\% (Chemotherapie-Arm). Die Frauen hatten etwa jeweils zur Hälfte triple-negative oder Hormonrezeptor-positive Karzinome. Auch in dieser Studie wurde mit dem PARP-Inhibitor ein um etwa 3 Monate verlängertes progressionsfreies Überleben erreicht, wobei dies nicht nur für die triple-negativen Tumoren galt, sondern auch für die Hormonrezeptor-positiven Tumoren. Ferner ergab sich in der EMBRACA-Studie ein tendenzieller Vorteil im medianen Gesamtüberleben für die mit Talazoparib behandelten Patientinnen (22,3 vs. 19,5 Monate).
Talazoparib hemmt vermutlich stärker das PARP-1-Enzym, was seine gute Wirksamkeit erklären könnte. Der PARP-Inhibitor scheint zudem gut verträglich zu sein, wie ein Vergleich der Erhebung des Global Health Status (GHS)/Quality of Life (QoL) zeigte: Mit Talazoparib wurde diesbezüglich eine Verbesserung erreicht, während sich mit der Kontroll-Chemotherapie der Gesundheitszustand verschlechterte [68]. Außerdem blieb die Lebensqualität unter Talazoparib-Therapie länger stabil als unter dem Vergleichsregime (Abb. 17).

\section{Strategien bei HER2-positivem $m B C$}

Die Empfehlungen für die Erstlinientherapie bei HER2-positivem mBC (HER2 = humaner epidermaler Wachstumsfaktorrezeptor 2) [63] sind auch für ältere Patientinnen gut anzuwenden. Vorzugsweise wird die doppelte Antikörperblockade mit Trastuzumab/Pertuzumab plus Chemotherapie eingesetzt (Abb. 18), wobei Docetaxel eine neurotoxische Komponente mitbringt. Ein Wechsel zu Paclitaxel bzw. Vinorelbin ist möglich, aber nicht weniger neurotoxisch.

In der Zweitlinientherapie steht nach Vorbehandlung mit Trastuzumab die Therapie mit Trastuzumab-Emtansin (T-DM1) ganz im Vordergrund. Als weitere Therapielinien kommen als zugelassener Standard Capecitabin plus Lapatinib oder (bei Hormonrezeptor-negativen Tumoren) die Kombination aus Trastuzumab und Lapatinib infrage, die aber für ältere Patientinnen problematisch sind. Sie können oft nur dosisreduziert appliziert werden, da schwere Diarrhöen auftreten können. Mit Tucatinib (ONT-380) könnte künftig eine verträgliche Therapiealternative zur Verfügung stehen. Der orale selektive HER2-Inhibitor ist in einer PhaseI-Studie bei stark vorbehandelten Patientinnen (median 5 Vorthe- 
Abb. 17. Lebensqualität (GHS/QoL) unter Talazoparib versus Physican's Choice of Therapy (PCT) beim mBC; modifiziert nach [70].
Statistically significant delay in the time to clinically meaningful deterioration* in GHS/QoL favoring TALA

\begin{tabular}{lll} 
& TALA 1 mg PO & PCT $(n=114)$ \\
& daily $(n=262)$ & \\
\hline Events, no. (\%) & $76(29 \%)$ & $48(42 \%)$ \\
\hline
\end{tabular}

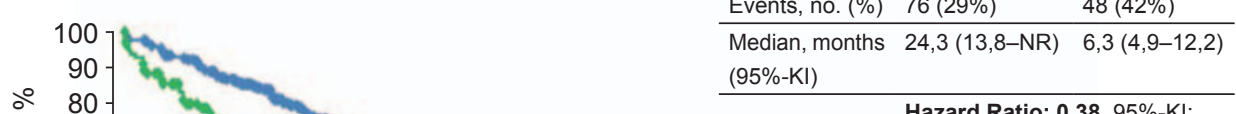

ㅇ $80-$ Hazard Ratio: 0,38, 95\%-KI:

$0,26-0,55 p<0,0001$
Erstlinientherapie beim HER2-positiven metastasierten Mammakarzinom

\begin{tabular}{|c|c|c|c|}
\hline & \multicolumn{3}{|c|}{ Oxford } \\
\hline & LoE & GR & AGO \\
\hline - Docetaxel + Trastuzumab + Pertuzumab & $1 \mathrm{~b}$ & A & ++ \\
\hline - Paclitaxel (wk) + Trastuzumab + Pertuzumab & $2 b$ & B & ++ \\
\hline - nab-Paclitaxel + Trastuzumab + Pertuzumab & $3 b^{a}$ & C & + \\
\hline - Vinorelbin + Trastuzumab + Pertuzumab & $3 b$ & B & + \\
\hline $\begin{array}{l}\text { - T-DM } 1 \text { (Rückfall innerhalb von } 6 \text { Monaten } \\
\text { und nach Taxan und Trastuzumab) }\end{array}$ & $2 b$ & B & + \\
\hline - $1^{\text {st }}$ line Chemotherapie* + Trastuzumab & $1 b$ & B & + \\
\hline - Trastuzumab mono & $2 b$ & B & $+1-$ \\
\hline - Taxan + Lapatinib & $1 b$ & B & $+1-$ \\
\hline - Taxan + Trastuzumab + Everolimus & $1 b$ & B & - \\
\hline - Trastuzumab + Aromatase-Inhibitoren (ER+) & $2 b$ & B & $+1-* *$ \\
\hline - Lapatinib + Aromatase-Inhibitoren (ER+) & $2 b$ & B & $+1-* *$ \\
\hline
\end{tabular}

Abb. 18. Empfehlungen für die Erstlinientherapie bei mBC; in Anlehnung an [63].

rapien) geprüft worden [69]. Tucatinib hat im Gegensatz zu Lapatinib keine über den EGFR vermittelten (unerwünschten) Wirkungen wie das verstärkte Auftreten von Diarrhöen und Hautreaktionen. Bei 22 vorbehandelten Patientinnen mit HER2-positivem mBC wurden zu 14\% partielle Remissionen erzielt [69].

Eine weitere Möglichkeit, das Risiko von neurotoxischen und gastrointestinalen Nebenwirkungen zu reduzieren bei zugleich hoher Effektivität der Therapie ist die Kombination von Trastuzumab mit Pembrolizumab. Der Checkpoint-Inhibitor Pembrolizumab könnte eine immunvermittelte Trastuzumab-Resistenz durchbrechen, so die Annahme [70]. Tatsächlich konnte bei Patientinnen, die bereits Pertuzumab und T-DM1 erhalten haben, mit
Endokrin-basierte Therapie der postmenopausalen Patientin mit HER2-negativem metastasiertem Mammakarzinom

\begin{tabular}{lccc}
\hline & \multicolumn{3}{c}{ Oxford } \\
& LoE & GR & AGO \\
\cline { 2 - 4 } - Letrozol* + Palbociclib & $1 \mathrm{~b}$ & $\mathrm{~B}$ & ++ \\
- Fulvestrant + Palbociclib & $1 \mathrm{~b}$ & $\mathrm{~B}$ & ++ \\
- Letrozol* + Ribociclib & $1 \mathrm{~b}$ & $\mathrm{~B}$ & ++ \\
- Letrozol /Anastrozol+ Abemaciclib & $1 \mathrm{~b}$ & $\mathrm{~B}$ & + \\
- Fulvestrant + Abemaciclib & $1 \mathrm{~b}$ & $\mathrm{~B}$ & + \\
- Abemaciclib Monotherapie & 3 & $\mathrm{C}$ & $+/-$ \\
- Exemestan + Everolimus & $1 \mathrm{~b}$ & $\mathrm{~A}$ & + \\
- Tamoxifen + Everolimus & $2 \mathrm{~b}$ & $\mathrm{~B}$ & + \\
- Letrozol + Everolimus & $2 \mathrm{~b}$ & $\mathrm{~B}$ & $+/-$ \\
- Fulvestrant + Everolimus & $2 \mathrm{~b}$ & $\mathrm{~B}$ & + \\
- CDK4/6i beyond progression & 5 & $\mathrm{D}$ & - \\
\hline * Daten können auf andere Als extrapoliert werden & & & \\
\hline
\end{tabular}

Abb. 19. Endokrin-basierte Erstlinientherapie beim mBC; in Anlehnung an [63].

dieser Kombination eine Remission bzw. Krankheitsstabilisierung (net clinical benefit) von $24 \%$ erzielt wurde.

Ein relevanter Faktor bei der Therapiefindung ist die Trastuzumab-induzierte Kardiotoxizität, die besonders für komorbide ältere Patienten ein möglicher Hinderungsgrund sein kann. Die Substanz DS8201 ist ein gegen HER2 gerichteter Antikörper, der mit einem Topoisomerase-Hemmer konjugiert ist [71]. In ersten Studien wurde mit dem Wirkstoff eine gute Ansprechrate bei verminderter Kardiotoxizität erzielt.

Sonderfall endokrine Therapie bei $m B C$

In der endokrin-basierten Erstlinientherapie postmenopausaler Patientinnen mit HER2-negativem mBC ist der Standard die Kombination mit einem CDK4/6-Inhibitor ( $\mathrm{CDK}=$ Cyclin-abhängige Kinase) wie Palbociclib oder Ridociclib (Abb. 19). 


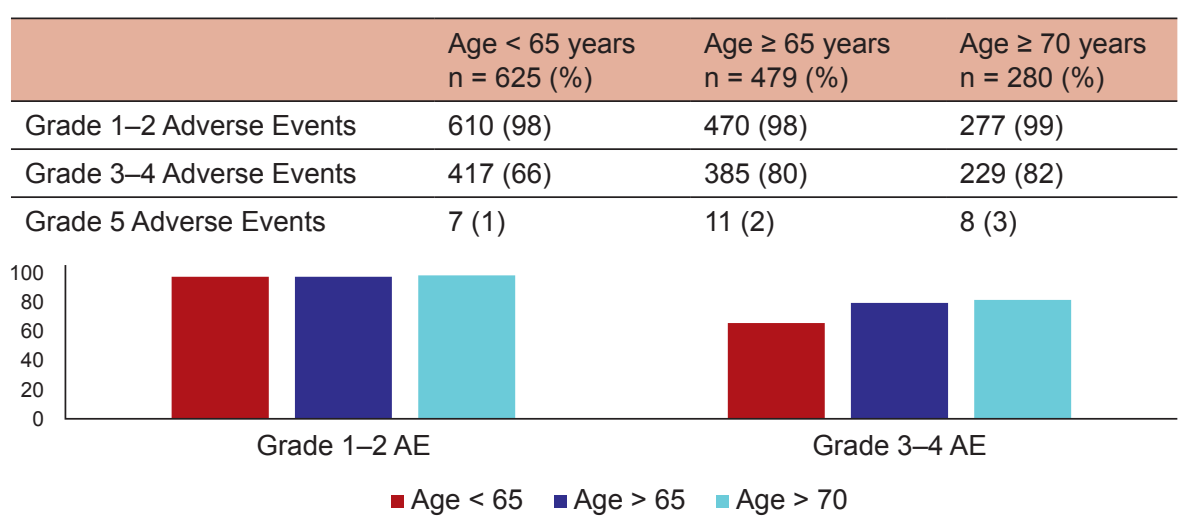

Abb. 20. Verträglichkeit von CDK4/6-Inhibitoren; modifiziert nach [77]. auszuweichen. Schließlich stehen für die endokrine Therapie bei mBC aktuell 2 CDK4/6-Inhibitoren zur Verfügung, die auch bei älteren Patientinnen wirksam und verträglich sind. Eine Beschränkung dieser Therapie auf bestimmte Patientengruppen nach definierten Kriterien ist derzeit nicht möglich; das Alter per se ist sicherlich kein Grund, auf eine solche Behandlung zu verzichten.

\section{Zukünftige Herausforderungen in der Versorgung älterer Patienten}

\section{Referent: Alexander Gebauer, Greifswald}

Das Institut für Community Medicine der Universitätsmedizin Greifswald hat im Auftrag der Deutsche Gesellschaft für Hämatologie und Medizinische Onkologie (DGHO) im Februar 2013 einen Schriftenband zu den Herausforderungen des demografischen Wandels im Hinblick auf die onkologische Versorgung veröffentlicht [77]. Dieser Schriftenband wird in diesem Jahr von der Zenwtralstelle der Krebsregistrierung in Greifswald (einem Teil des klinischen Krebsregisters Mecklenburg-Vorpommern) in Zusammenarbeit mit der DGHO aktualisiert. Die ursprüngliche Arbeit basiert auf den Inzidenzen und Prävalenzen von Krebserkrankungen im Jahr 2008, die für das Jahr 2020 auf Landkreisebene hochgerechnet wurden. Dies diente als Grundlage für Überlegungen, wie sich die Krebsmorbidität über die Jahre verändern wird und welche Auswirkungen das auf die (regionale) onkologische Versorgung im Jahr 2020 haben dürfte. Über die Vorhersagen zu den Inzidenzen und Prävalenzen wurden außerdem Schätzungen zur Krankenhausbelegung, zum Bedarf an ambulanter Versorgung und zu den Krankheitskosten in 2020 vorgenommen. Dem neuen, in 2018 zu erstellenden Gutachten werden die Bevölkerungsdaten der Statistischen Ämter der Bundesländer aus dem Jahr 2014 zugrunde liegen [78] sowie die zugehörigen Bevölkerungsprognosen für 2025 unter der Annahme einer stärkeren $\mathrm{Zu}$ wanderung auf Landkreisebene. Dies erfolgt getrennt nach Geschlecht und 5-Jahres-Altersgruppen. Vom Zentrum für Krebsregisterdaten (ZfKD) am Robert Koch-Institut werden die Daten zur absoluten Anzahl der Neuerkrankungen je Krebsart zur Verfügung gestellt, und es wurde die jeweilige rohe (nicht altersstandardisierte) Rate/100 000 Einwohner getrennt nach Geschlecht und 5-JahresAltersgruppen auf Landkreisebene übermittelt. 


\section{In 2025 werden die Menschen in Deutschland im Schnitt älter} sein

Insgesamt wird die Gesamtbevölkerung Deutschlands verglichen mit 2014 in 2025 annähernd gleich bleiben (Zuwachs um $+0,3 \%)$. Die Tendenz ist im weiteren Verlauf jedoch rückläufig. Sowohl einige östliche als auch westliche Bundesländer müssen bis 2025 einen Bevölkerungsrückgang von voraussichtlich bis zu 5\% hinnehmen. Im Gegensatz dazu wird es im Süden Deutschlands sowie in Hamburg und Berlin laut der Prognose für 2025 leichte

Abb. 21. Die Zahl älterer Menschen nimmt zu.

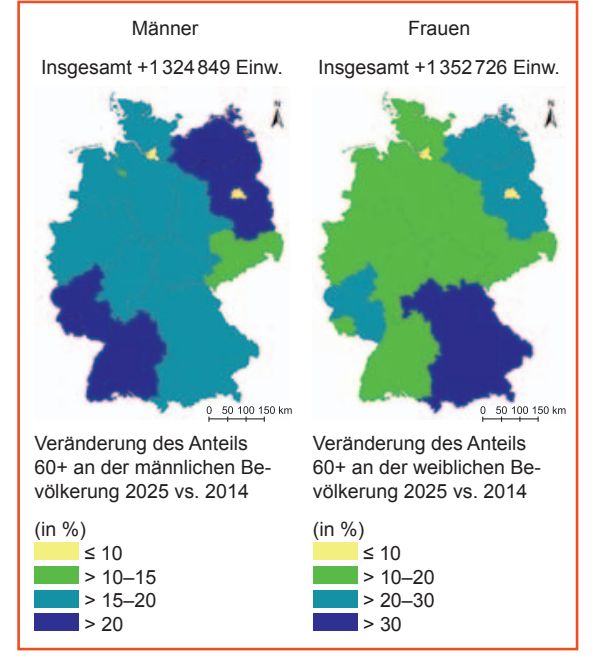

(in den beiden Großstädten auch höhere) Bevölkerungszuwächse geben. Der Anteil der über 60-Jährigen wird jedoch in allen Bundesländern steigen (Abb. 21). Insgesamt werden im Jahr 2025 in Deutschland über 2,6 Millionen mehr Menschen in der Altersgruppe der über 60-Jährigen leben als im Jahr 2014.

Noch deutlicher steigt der Anteil der über 80-Jährigen, deren Anteil im Osten Deutschlands und in Bayern im Jahr 2025 um 4050\% höher sein wird als im Jahr 2014.

\section{Im Jahr 2025 wird es mehr Krebserkrankungen geben}

Bezogen auf die Häufigkeit der einzelnen Krebserkrankungen lassen sich beim Vergleich der einzelnen Entitäten untereinander ebenfalls Veränderungen erkennen. In 2014 waren die malignen Melanome der Haut bei Männern die fünfthäufigste Krebserkrankung und sind damit von Platz 8 in 2008 deutlich aufgerückt (geschätzte Zahl der Neuerkrankungen mit malignem Melanom im Jahr 2014: 10 910) [2]. Die 5 häufigsten Krebsarten bei Männern betrafen 2014 die Prostata, die Lunge, den Dick- und Enddarm, die Harnblase und die Haut. Bei Frauen waren am häufigsten die Brustdrüse, der Dick- und Enddarm, die Lunge, die Gebärmutter und die Haut betroffen (Reihenfolge der Häufigkeit gegenüber 2008 unverändert). Bei beiden Geschlechtern steigt die Krebserkrankungsrate mit dem Alter an, wobei die Erkrankungsrate (erhoben in den Jahren 2012-2014 je 100000 Einwohner) ab etwa der Lebensmitte bei Männern deutlicher steigt als bei Frauen. Die ab-
Abb. 22. Prävalenz der Krebserkrankungen bei Männern und Frauen in den Jahren 2014 und (geschätzt) 2025.

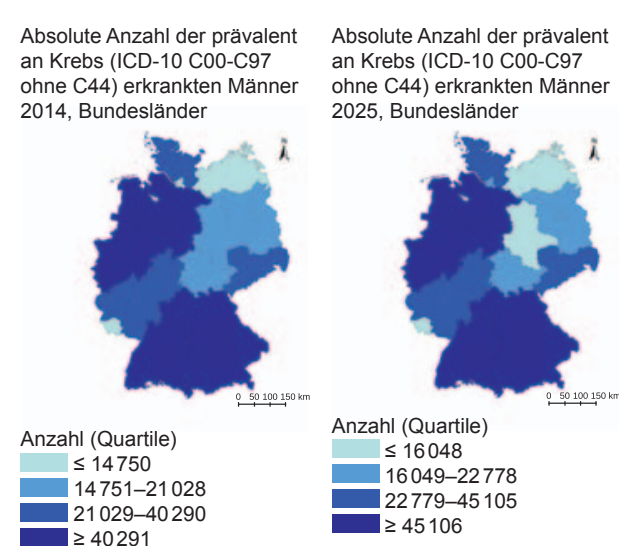

Veränderung der absoluten Anzahl der prävalent an Krebs (ICD-10 C00-C97 ohne C44) erkrankten Männer 2025 vs. 2014 Insgesamt +66504 Fälle $(+10 \%)$

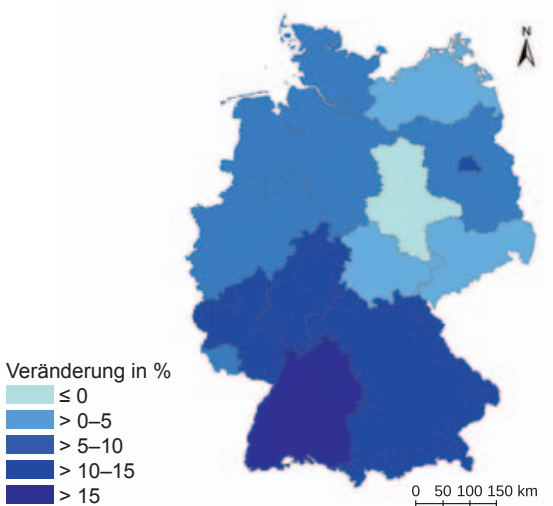

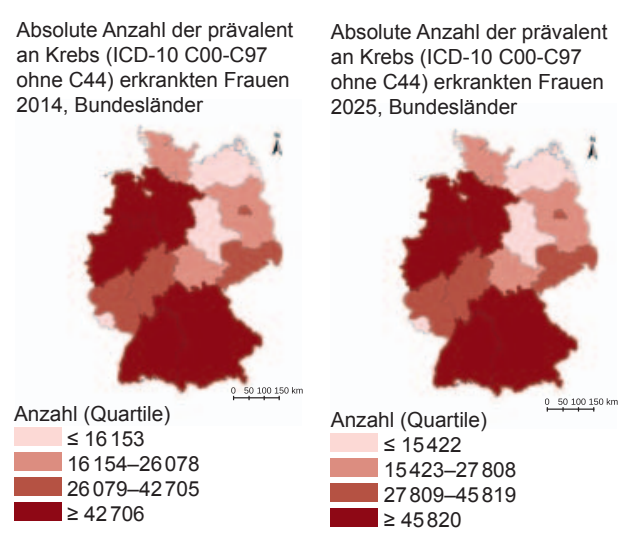

Veränderung der absoluten Anzahl der prävalent an Krebs (ICD-10 C00-C97 ohne C44) erkrankten Frauen 2025 vs. 2014 Insgesamt +40.573 Fälle $(+6 \%)$
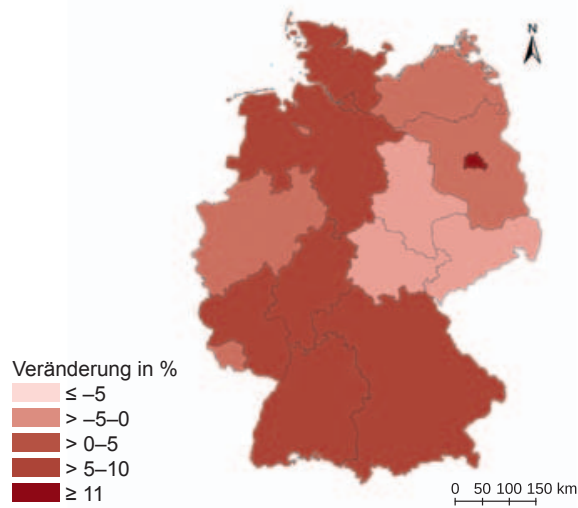


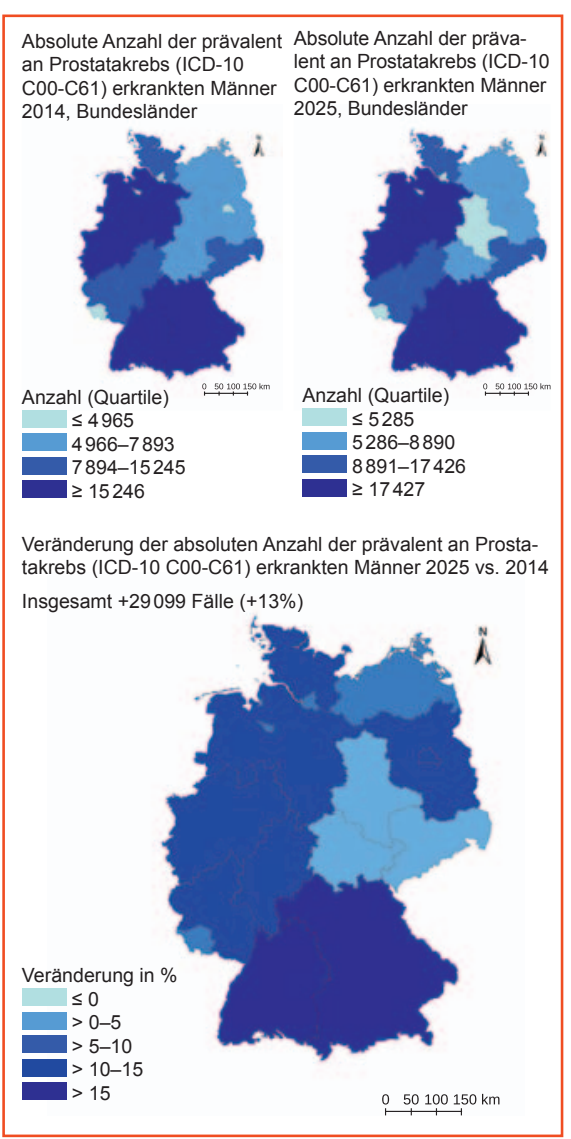

solute Anzahl an Krebsneuerkrankungen wird im Jahr 2025 bei Männern um etwa 16\% (geschätzt +37521 Fälle) und bei Frauen um 12\% (geschätzt +25 874 Fälle) höher liegen als im Jahr 2014 Bezogen auf einzelne Krebsarten wird zum Beispiel beim Lungenkrebs der Männer eine Steigerung um 16\% und bei den kolorektalen Tumoren der Frauen um 17\% erwartet.

Die Prävalenz gibt die Anzahl der Erkrankten zu einem bestimmten Zeitpunkt in einer bestimmten Population an. Die dafür benötigten Daten wurden vom ZfKD am Robert Koch-Institut bereitgestellt. Die Berechnung erfolgte auf Basis der Fallzahlen der Krebsneuerkrankungen von 2009-2014 und der zum 31.12.2014 noch lebenden Patienten. Aus den dazugehörigen rohen Raten wurde dann die Prognose für 2025 erstellt, die zeigt, dass die Prävalenz sowohl für Männer als auch für Frauen zunehmen wird (Abb. 22).

Besonders stark fällt der Anstieg bei Prostatakrebs aus (Abb. 23), an dem Ende des Jahres 2025 fast 30000 Männer mehr erkrankt sein werden als zum 31.12.2014. Dies wäre ein Anstieg von $13 \%$. Verglichen damit würde der Anstieg beim Brustkrebs der Frauen mit 5\% (etwa 13000 mehr erkrankte Frauen als in 2014) deutlich geringer ausfallen.

Anhand der vorliegenden Daten lässt sich mit Sicherheit vorhersagen, dass es in den nächsten 10 Jahren zu einer deutlichen $\mathrm{Al}$ terung der Bevölkerung kommt. Insbesondere der Anteil der Gruppe der über 80-Jährigen wird stark ansteigen. Es werden im Jahr 2025 über 540000 mehr Männer und über 960000 mehr Frauen mit einem Alter von über 80 Jahren in Deutschland leben als im Jahr 2014. Dies ist auch die Ursache dafür, dass die Zahl der Krebsneuerkrankungen im Jahr 2025 etwa 63000 über der von 2014 liegen wird. Die stärksten Zuwachsraten wird es bei den Krebsarten mit einem Altersgipfel im höheren Lebensalter geben, wie z.B. bei den Prostatakarzinomen. Dies hat auch zur Folge, dass die Krebsprävalenz zunehmen wird und im Jahr 2025 um etwa 107000 höher liegen wird als im Jahr 2014.

Mit der im Jahr 2018 durchzuführenden Prognose für 2025 sollen bevölkerungsbezogene Inzidenzen für die jeweils 10 häufigsten, nach Altersgruppen unterteilten Krebserkrankungen bei Männern und Frauen auf Landkreisebene vorgelegt werden. Diese Berechnungen werden auf Grundlage der Daten von 2014 durchgeführt. Ferner soll für die besagten Krebserkrankungen eine Hochrechnung der bevölkerungsbezogenen 5-Jahres-Prävalenzen erfolgen und darauf aufbauend die Hochrechnung der 10-Jahres-Prävalenzen. Darüber hinaus soll die Komorbiditätslast bei Tumorpatienten (je nach Datenlage für Diabetes, Demenz, Herzkreislauferkrankungen, Niereninsuffizienz, Adipositas, COPD) untersucht und die Rolle der klinischen Krebsregister für die onkologische Versorgung und Qualitätssicherung eingeschätzt werden.

\section{Kriterien der Therapieentscheidung bei älteren Patienten}

\section{Referent: Carsten Bokemeyer, Hamburg}

Die mittlere Lebenserwartung eines neugeborenen Menschen hat sich seit dem Beginn des 20. Jahrhunderts um fast 30 Jahre verlängert. Die im Jahr 2009 und danach Geborenen dürften im Mittel 100 Jahre alt werden und die mittlere Lebenserwartung steigt kontinuierlich weiter an. Trotz der Erfolge onkologischer Therapien in den letzten Jahren resultiert daraus eine Zunahme an Tumorerkrankungen, weil insbesondere der immer größer werdende Teil der älteren Bevölkerung davon betroffen ist [79]. Aufgrund therapeutischer Fortschritte steigt die Krebsmortalität jedoch nicht im gleichen Maße an oder geht sogar zurück, wie dies etwa beim Brustkrebs der Fall ist [80]. Insgesamt werden heute in Deutschland fast 2 von 3 Krebspatienten von ihrer Erkrankung geheilt. Ein besseres Langzeitüberleben wurde aber vor allem in den jüngeren Altersgruppen erreicht [80]. Bei den 20- bis 40-Jährigen werden heute Heilungsraten von $60-80 \%$ avisiert.

Das Alter selbst ist als Entscheidungskriterium für eine onkologische Therapie nicht geeignet. Die WHO orientiert sich bei ihrer Einteilung rein am chronologischen Alter und ordnet die 61- bis 75-Jährigen als «ältere Menschen» ein, die 76- bis 90-Jährigen als «alte Menschen» und die über 90-Jährigen als «sehr alte Menschen». Diese 3 Gruppen sind aber aus biologischer Sicht sehr heterogen, was bei Entscheidungen etwa zur Therapiefähigkeit berücksichtigt werden muss.

Einen einfach zu bestimmenden Biomarker, der das Alter definiert und damit objektiviert, haben wir nicht, auch wenn es immer wieder Ansätze zur Entwicklung entsprechender Bluttests wie etwa zum Nachweis des p16-Proteins in T-Lymphozyten gibt [81]. Das 


\section{Besonderheiten älterer Patienten mit}

Tumorerkrankungen

- Heterogene Gruppe, deren Eigenschaften von «fit» bis «gebrechlich» reichen können

- Faktoren mit Einfluss auf die Therapiefähigkeit: z.B. Allgemeinzustand, Komorbidität,

Abhängigkeit in Verrichtungen des täglichen Lebens, veränderte Organfunktion (z.B. veränderte Knochenmarksreserve,veränderte

Pharmakodynamik)

- Ältere Patienten sind in Studien unterrepräsentiert oder stellen eine sehr selektierte Gruppe aus der Gesamtkohorte dar; somit sind Ergebnisse aus klinischen

Abb. 24. Ältere Patienten in der Onkologie.

praktische Vorgehen in der geriatrischen Onkologie ist deshalb immer auch von subjektiven Eindrücken geprägt. Konfrontiert werden Onkologen mit dieser Problematik nahezu täglich: Die Hälfte aller Krebsfälle werden bei Menschen über 65 Jahre diagnostiziert, die Tumoren dieser Patienten sind zu 50\% bereits fortgeschritten und mehr als 65\% der tumorbedingen Todesfälle treten in dieser Altersgruppe auf.

Wer wird womit behandelt und was ist das Ziel?

Die Gruppe der älteren Krebspatienten weist eine Reihe von Besonderheiten auf (Abb. 24), die therapeutische Konsequenzen haben können. Wie immer diese auch aussehen mögen, so wollen in der Regel auch ältere Patienten über ihre Krankheit und deren Behandlung umfassend informiert sein [82]. Wie gut diese Informationsvermittlung gelingt, hängt natürlich auch von den kognitiven Fähigkeiten des älteren Patienten und den didaktischen Fähigkeiten des Informanten ab.

Letztlich geht es bei älteren Krebspatienten darum, ihren Gesundheitszustand zu erkennen (wer ist therapiefähig?), Therapien mit hoher Toxizität zu vermeiden (wie soll behandelt werden?) und das krebsspezifische Überleben in den Kontext der allgemeinen Lebenserwartung zu stellen (welches Ziel wird mit der Therapie angestrebt?). Um diese Fragen möglichst objektiv beantworten zu können, sind geriatrische Assessments hilfreich. Neben den in der Onkologie gebräuchlichen Scores wie der Karnofsky-Index oder der Eastern Cooperative Oncology Group(ECOG)-Performance-Status sollten weitere Assessment-Scores hinzugezogen werden, die geriatrische Aspekte gezielter abfragen (Abb. 25).

Während bei unter 65-jährigen Patienten ein schlechter Performance-Status und/oder ausgeprägte Komorbiditäten relativ selten sind und deshalb in der Gesamtgruppe kaum ins Gewicht fallen, sind diese Beeinträchtigungen im Alter häufig und wirken sich entsprechend stark auf die Therapiewahl aus [83]. Von über 1200 älteren Patienten mit KRK waren nur 14\% frei von relevanten Komorbiditäten, körperlichen Einschränkungen oder einem geriatrischen Syndrom [83], was den Stellenwert eines sorgfältigen geriatrischen Assessments unterstreicht. Ein solches Vorgehen ermöglicht die Einteilung der Patienten in Gruppen mit unterschiedlicher Therapiefähigkeit, wie dies von Balducci und Extermann [39] exemplarisch vorgenommen worden ist.

\begin{tabular}{ll}
\hline Onkologie & Geriatrie \\
\hline Alter & $\begin{array}{l}\text { Funktioneller Status } \\
\text { (z.B. ADL, IADL) }\end{array}$ \\
\hline $\begin{array}{l}\text { Performance } \\
\text { Status, z.B. } \\
\text { Karnofsky oder } \\
\text { ECOG-PS }\end{array}$ & $\begin{array}{l}\text { Depression (z.B. Geri- } \\
\text { atric Depression Scale) }\end{array}$ \\
\hline & \\
\hline & Demenz (z.B. Mini- \\
& Mental-Status-Exam) \\
& Timed Up and Go) \\
\hline & Ernährung (z.B. Mini- \\
& Nutritional Assessment) \\
\hline & Soziale Situation (z.B. \\
& F-Sozu) \\
\hline & Komorbiditäten und \\
& Polypharmazie (z.B. \\
Charlson-Score)
\end{tabular}

\section{$I N-G H O^{\circledR}$-Register enthält Daten älterer Patienten}

Um die Heterogenität der Gruppe der älteren Patienten besser erfassen zu können und ein Instrument («IN-GHO FIT») zur Abschätzung ihrer Therapiefähigkeit zu entwickeln, wurde von der DGHO-Arbeitsgruppe Geriatrische Onkologie das IN-GHO-Register angelegt. Es enthält Daten von mehr als 3000 älteren Tumorpatienten. Weitere Ziele des Registers sind die Untersuchung und der Vergleich des Patientenaufkommens in den verschiedenen Versorgungsstrukturen (Klink, Praxis), die Untersuchung der Umsetzbarkeit und Praktikabilität eines geriatrischen Assessments im klinischen Alltag und die Schaffung einer Datengrundlage zur besseren Abschätzung der Therapiefähigkeit. In das Register wurden ältere Patienten ( $\geq 70$ Jahre) mit Tumorerkrankung aufgenommen, bei denen eine Therapieentscheidung anstand. Im Rahmen der Ausgangserhebung wurde ein Basisdatensatz angelegt und ein geriatrisches Assessment durchgeführt. Nach 6-8 Wochen wurde der Verlauf dokumentiert. Die Abschlusserhebung nach etwa 6 Monaten beschrieb nochmals den Patientenstatus einschließlich der Versorgungssituation und des aktuellen Tumorbefunds.

Die Auswertung einer 200 Patienten umfassenden Pilotgruppe des Registers zeigte hinsichtlich der Therapiefähigkeit, dass die behandelnden Ärzte immerhin 60\% der Patienten als uneingeschränkt therapiefähig einschätzten, während nach dem Schema von Balducci und Extermann [39] nur 27\% der Patienten diese Zuordnung erhielten. Auf die Gruppe 3 (gebrechlich) entfielen nach ärztlicher Beurteilung 11\% und nach dem von Balducci und Extermann beschrieben Vorgehen 37\% der Patienten. Bei den IN-GHORegisterpatienten korrelierten Outcome-Parameter wie «höhergradige Toxizität», «Therapiedurchführbarkeit» und «Tod innerhalb von 6 Monaten» gut mit den erhobenen Daten etwa zur Belastbarkeit durch die Selbsteinschätzung der Patienten und der Gebrechlichkeit im Arzturteil. Das numerische Alter dagegen war mit keinem dieser Endpunkte assoziiert. Die Gesamtheit der Registerpatienten, deren Auswertung derzeit vorgenommen wird, repräsentiert ein breites Spektrum an älteren Krebspatienten; bei etwa einem Drittel war eine kurative Therapie vorgesehen, die ganz überwiegend medikamentös erfolgen sollte, und zwar zu 59\% als onkologi- 
Abb. 26. Einfluss des Alters auf pharmakologische Parameter; modifiziert nach [39].
Alter beeinflusst die Toxizität und Effektivität der Chemotherapie

- Im Alter veränderte pharmakokinetische Parameter:

- Veränderte Verteilungsvolumina (Fettgewebsanteil $\uparrow$, Gesamtkörperwasser $\downarrow$ )

- Abnahme der renalen Filtrationsleistung

- Reduktion der intestinalen Mukosaoberfläche, Resorptionsfähigkeit $\downarrow$

- Im Alter potentiell veränderte pharmakodynamische Parameter:

- Höhere Expression des multi drug resistance genes (MDR), höhere Resistenz gegen Zytostatika

- Verminderte DNA-Reparaturmechanismen, verminderte Apoptoseinduktion

- Höhere Rate an Tumorhypoxie

- Verringerte Zellproliferation, Induktion von Seneszenz

sche Kombinationstherapie. Fast $80 \%$ der Registerpatienten wurden ambulant behandelt. Ein Viertel von ihnen war über 80 Jahre alt. 74\% hatten solide Tumoren. Die Mortalität in den ersten 6 Monaten betrug 30\%. Im geriatrischen Assessment wurden 30\% der Patienten als fit (uneingeschränkt therapiefähig) eingeschätzt, laut ärztlicher Beurteilung waren es $62 \%$ und in der Selbsteinschätzung durch den Patienten 52\%. Die avisierten Therapien konnten bei $63 \%$ der Patienten durchgeführt werden, wobei etwa die Hälfte der Ärzte das Ergebnis des geriatrischen Assessments in ihre Therapieentscheidung miteinbezogen, sodass bei etwa 40\% der Patienten die Therapie angepasst wurde.

\section{Geriatrisches Assessment beeinflusst die Therapieentscheidung}

Auch in einer US-amerikanischen Untersuchung [84] führten interdisziplinäre Fallbesprechungen unter Bezugnahme auf ein geriatrisches Assessment zur Änderung der Therapieentscheidung in $21 \%$ der Fälle, wobei in $80 \%$ eine weniger intensive Therapie gewählt wurde. Wichtigste Risikofaktoren für eine reduzierte Therapiefähigkeit waren die verminderte Fähigkeit, an Aktivitäten des täglichen Lebens teilzunehmen (niedriger ADL-Score; ADL = activities of daily living), und Mangelernährung. Bei geriatrischer Mitbeurteilung erhielten $31 \%$ der Patienten eine Medikationsänderung, 36\% eine psychologische Mitbetreuung, $42 \%$ eine Physiotherapie, $46 \%$ eine Betreuung durch den Sozialdienst und $70 \%$ eine Ernährungsberatung.

Ob sich die Toxizität der Therapieschemata vorhersagen lässt, wurde in der Studie CRASH (Chemotherapy Risk Assessment Scale for High-Age Patients) bei 518 US-amerikanischen Krebspatienten im Alter von im Median 76 Jahren untersucht [85]. Prädiktive Faktoren für eine höhere Toxizität der Chemotherapie waren außer den tumor- und therapiespezifischen Gegebenheiten unter anderem das Geschlecht, das Lebensalter, der Body Mass Index (BMI), der diastolische Blutdruck und der ECOG-PerformanceStatus. Die Autoren entwickelten daraufhin einen Score, mit dem sich das Ausmaß der zu erwartenden Therapietoxizität ableiten

\begin{tabular}{|c|c|}
\hline $\begin{array}{l}\text { Prädiktive Faktoren für Toxizität } \\
\text { - Alter } \geq 73 \text { Jahre }\end{array}$ & $\mapsto$ Alter \\
\hline $\begin{array}{l}\text { - GI/GU Tumor } \\
\text { - Standarddosis } \\
\text { - Polychemotherapie }\end{array}$ & $\rightarrow$ Tumor/ \\
\hline $\begin{array}{l}\text { - Hämoglobin }(m<11, w<10) \\
\text { - Kreatinin-Clearance }\end{array}$ & $\rightarrow$ Labor \\
\hline $\begin{array}{l}\text { - Stürze letzte } 6 \text { Monate } \\
\text { - Hörminderung } \\
\text { - Verminderte Gehstrecke } \\
\text { (<500m) } \\
\text { - Hilfe bei Medikamenten- } \\
\text { einnahme (IADL) } \\
\text { - Eingeschränktes Sozialleben }\end{array}$ & $\rightarrow$ Geriatrisches \\
\hline
\end{tabular}

Abb. 27. Prädiktive Faktoren für Medikamententoxizität; modifiziert nach [90].

lässt. Die Studienteilnehmer hatten unter Therapie zu 32\% eine Hämatotoxizität Grad IV und zu 56\% eine nichthämatologische Toxizität Grad III/IV. In einer weiteren Arbeit wurde untersucht, ob sich mithilfe eines geriatrischen Assessments die Mortalität unter einer Erstlinienchemotherapie innerhalb der ersten 6 Monate abschätzen lässt [86]. Ein höheres Mortalitätsrisiko hatten Männer (Odds Ratio (OR) 2,4), Patienten mit fortgeschrittenen Tumoren (OR 3,9), mangelernährte Patienten (OR 2,77) und immobile Patienten (OR 2,55).

Die Effektivität und Toxizität einer Pharmakotherapie werden von den biologischen Veränderungen im höheren Lebensalter beeinflusst (Abb. 26), insbesondere im Zusammenhang mit einer eingeschränkten Nierenfunktion. Durch die im Alter häufigere Vaskulopathie ist die glomeruläre Filtrationsleistung herabgesetzt, was zur Akkumulation nephrotoxischer oder renal eliminierter Medikamente wie Cisplatin und Capecitabin führen kann. Komorbiditäten wie Herzinsuffizienz, Diarrhö und Exsikkose vermindern das intravasale Volumen und schränken die Nierenfunktion weiter ein, was insbesondere zusammen mit der Gabe von Medikamenten aus der Gruppe der nichtsteroidalen Antirheumatika (NSAR) und der Aminoglykoside kritisch werden kann. Die International Society of Geriatric Oncology (SIOG) hat deshalb vor einigen Jahren Leitlinien zur Medikamentendosierung bei älteren Krebspatienten mit Niereninsuffizienz publiziert [87].

Schließlich haben Hurria et al. [88] im Rahmen einer Multicenter-Studie eine Reihe von prädiktiven Faktoren identifiziert, die mit einer erhöhten Toxizität von Chemotherapien bei älteren Patienten korrelieren (Abb. 27). Neben den bekannten Einflussparametern sind dies auch singuläre, oft nur über das geriatrische Assessment zu erfassende Merkmale wie Hörvermögen, Sturzfrequenz und Ausprägung des Soziallebens. Eine Abschätzung der Therapiefähigkeit sollte mindestens die Faktoren Alter, Allgemeinzustand, Selbständigkeit der Lebensführung, Selbsteinschätzung des Patienten und Komorbidität berücksichtigen.

$\mathrm{Zu}$ beachten sind ferner Arzneimittelinteraktionen, die besonders bei Patienten mit Polypharmazie auftreten können [89]. Sie ist bei älteren Menschen häufig, wie etwa das PRISCUS-Projekt gezeigt hat: Demnach nehmen ältere Menschen durchschnittlich 3,6 rezeptpflichtige Medikamente ein sowie zusätzlich selbsterworbene Präparate [90]. Mindestens ein Viertel der Arzneimittelverordnungen sind nicht nötig, vermuten die Autoren. 
Die britische FOCUS-2-Studie ging Fragen zur Effektivität und Lebensqualität älterer Krebspatienten unter einer Standardchemotherapie nach [91]. An der Untersuchung nahmen 459 Patienten mit metastasiertem KRK teil, die aufgrund ihres hohen Lebensalters oder wegen Gebrechlichkeit keine volldosierte Kombinationschemotherapie erhielten. Die randomisierte Multicenter-Studie im $2 \times 2$ faktoriellen Design prüfte 5-Fluorouracil (5-FU), 5-FU plus Oxaliplatin sowie Capecitabin und Capecitabin plus Oxaliplatin, jeweils mit einer Anfangsdosis von 80\% und der Möglichkeit zur Dosiserhöhung 6 Wochen nach Therapiebeginn bei geringer Nebenwirkungsrate. Als primärer Endpunkt verbesserte die Zugabe von Oxaliplatin die Effektivität gemessen am progressionsfreien Überleben und am Gesamtüberleben in beiden Therapievarianten signifikant. Eine Dosiserhöhung war unter 5-FU-Monotherapie bei etwa der Hälfte der Patienten möglich und bei 30-40\% der Patienten, die Capecitabin oder eine der Kombinationschemotherapien erhielten. Insgesamt waren die Therapien mit einer Anfangsdosis von $80 \%$ sicher und die Toxizität war vergleichbar mit einer vollen Dosierung vergleichbarer Therapien bei jüngeren Patienten. Capecitabin war zwar ähnlich effektiv, aber toxischer als 5-FU. Oxaliplatin verbesserte das Therapieergebnis, jedoch war das Gesamtüberleben der Studienteilnehmer deutlich verkürzt gegenüber üblichen (jüngeren) Studienkollektiven.

\section{Tumorbiologie gewinnt für die Therapieentscheidung an Bedeutung}

Festzuhalten bleibt, dass ein geriatrisches Assessment als Ergänzung zum krankheitsspezifischen Assessment helfen kann, geeignete Patienten für eine Therapie auszuwählen, wobei erste Untersuchungen für ein Einbeziehen der Patientenselbsteinschätzung sprechen. Ein reduzierter Allgemeinzustand, Komorbidität, herabgesetzte Nierenfunktion und weitere biologische Parameter sind mit erhöhter Toxizität einer medikamentösen Tumortherapie assoziiert. Zeichen der Gebrechlichkeit (ADL-Einschränkung), die Selbsteinschätzung des Patienten als «wenig belastbar» und Laborparameter (erhöhtes C-reaktives Protein (CRP), niedriges Albumin) sind generell mit einem schlechteren krebsspezifischen Überleben assoziiert.

Die klassische Einteilung von Patienten nach dem Balducci/Extermann-Schema bzw. in «go go», «slow go» und «no go» mag für Studienzwecke weiterhin sinnvoll sein, im klinischen Alltag sollten aber zunehmend auch biologische und molekulare Tumormerkmale berücksichtigt werden, um etwa in der CLL-Therapie möglichst vielen Patienten die wirksamsten Kombinationen anbieten zu können [41, 92, 93]. Neue Substanzen wie die TyrosinkinaseInhibitoren, monoklonale Antikörper und Immuntherapien haben andere Toxizitäten als die klassischen Chemotherapien, sodass dem geriatrischen Assessment hier womöglich eine andere Bedeutung zukommt. Offenbar ist aber das Alter ( $>65$ Jahre) auch bei einer Immunchemotherapie ein für das Überleben relevanter negativer Prognosefaktor [94], jedoch besteht hierzu noch erheblicher Forschungsbedarf, um zukünftig eine bessere und evidenzbasierte Versorgung der rasch ansteigenden Gruppe älterer Krebspatienten zu erreichen.

\section{Wirtschaftlichkeit: Sprengen alte Patienten das Budget?}

\section{Referent: Reinhard Busse, Berlin}

Seit Jahren steigen die Kosten im Gesundheitswesen und es wird heftig diskutiert, wo die Gründe dafür zu suchen sind. So wurden in Deutschland im Jahr 2015 fast 340 Milliarden EUR für die Prävention, Diagnose und Behandlung von Krankheiten ausgeben, wobei etwa die Hälfte der Kosten auf die über 65-Jährigen entfiel. Vor dem Hintergrund der sich verändernden Altersstruktur stellt sich die Frage, ob mit dem wachsenden Anteil alter Menschen auch die Gesundheitskosten exponentiell wachsen, womöglich sogar exponentiell, und diese damit «das Budget sprengen». Auf den ersten Blick scheint dies so zu sein. Die Organisation für wirtschaftliche Zusammenarbeit und Entwicklung (OECD) hat das Lebensalter in Korrelation zu den Gesundheitsausgaben in Prozent des Bruttoinlandproduktes (BIP) gesetzt und ermittelt, dass im OECD-Mittel 10\% (Deutschland: 11\%) des BIP auf Gesundheitsausgaben entfallen. Mit nur etwa 3\% des BIP sind die Gesundheitskosten für Kinder im Alter von etwa 10 Jahren am geringsten und mit etwa $18 \%$ für die etwa 85 -Jährigen am höchsten.

Dies spiegelt sich in den $\mathrm{Zu}$ - und Abschlägen für Alters- und Geschlechtsgruppen aus dem Risikostrukturausgleich (RSA) des Gesundheitsfonds. Am so besehen "günstigsten» aus Sicht der gesetzlichen Krankenkassen sind die 25- bis 29-jährigen Männer und am «teuersten» die 85- bis 89-jährigen Frauen [95]. Nun stellt sich die Frage, ob in der Gruppe der alten Menschen mehr Kranke sind und/oder die Kranken unter ihnen «kränker» und somit «teurer» sind als Kranke aus anderen Altersgruppen. Die Datenauswertung von fast 1,8 Millionen Patienten aus schottischen Hausarztpraxen hat gezeigt, dass beides zutrifft: Die ältere Bevölkerung ist zu einem höheren Teil krank und die Älteren sind verhältnismäßig häufig multimorbid [96]. Die häufigsten Komorbiditäten bei Krebserkrankungen waren in dieser Untersuchung Schmerzsyndrome, Depressionen und koronare Herzkrankheit.

\section{Auf Krebstherapien entfallen etwa 7\% der Gesamtkosten}

Die Gesamtkosten für Ältere ergeben sich aus den Kosten pro älterem Patient und dem Anteil an Kranken in diesem Alter. Krebserkrankungen verursachen relativ hohe Therapiekosten und sind deshalb trotz der (im Vergleich zu koronarer Herzkrankheit oder Diabetes) geringen Zahl an Patienten ein relevanter Kostenfaktor [96]. In einer französischen Studie waren bezogen auf die Gesamtbevölkerung Krebserkrankungen ähnlich kostenintensiv wie psychiatrische Erkrankungen und chronische kardioneurovaskuläre Erkrankungen; am teuersten allerdings waren Krankenhausaufnahmen wegen akuter Erkrankungen. Ähnliche Kostenvergleiche wurden für Deutschland bisher nicht vorgenommen. Vom Statistischen Bundesamt wurden für das Jahr 2015 die Ausgaben pro Krankheit und Altersgruppe beziffert, wonach 7\% (23 Milliarden der Gesamtkosten) auf die Behandlung von Krebserkrankungen entfielen. Aufgeschlüsselt nach einzelnen Krebsarten waren bösartige Neubildungen der 
GKV - Morbiditätsorientierter Risikostrukturausgleich

10 größte Zuweisungsvolumina nach Krankheitsgruppen in Milliarden EUR 2016* - Bundesgebiet

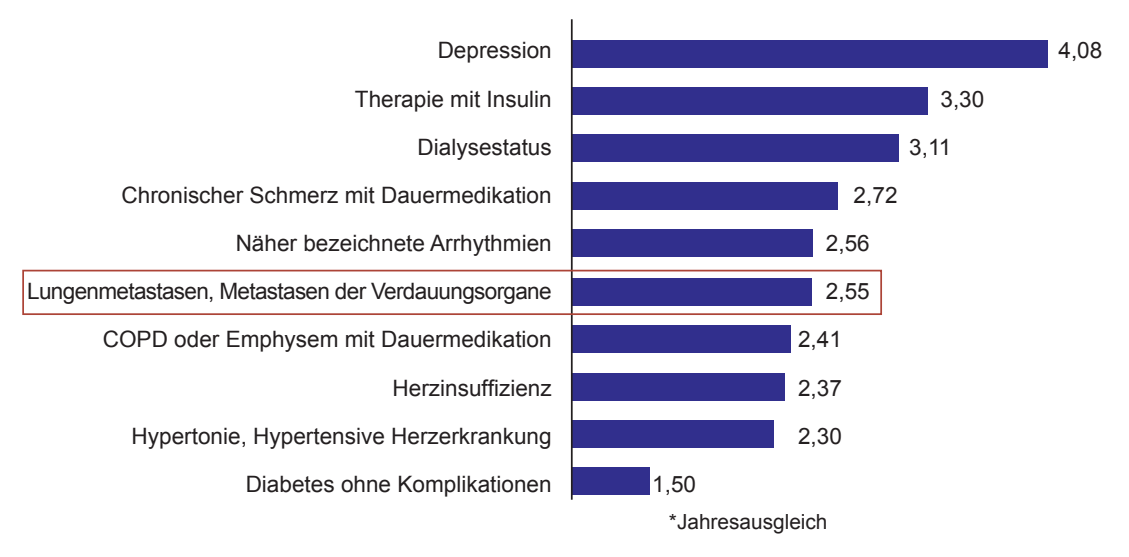

Abb. 28. Zuweisungsvolumen entsprechend dem Morbi-RSA (Daten des BVA).

Verdauungsorgane am kostenintensivsten, gefolgt von Mammakarzinom und Prostatakarzinom.

Die nach dem Lebensalter aufgeschlüsselten Kosten wurden dabei nicht pro Kopf berechnet, sondern für die jeweilige Gruppe. Demnach entfielen 60\% der für Krebserkrankungen aufzuwendenden Kosten auf Patienten ab 65 Jahre (während es über alle Krankheiten nur 50\% waren). Einen direkteren Zusammenhang zwischen dem Alter eines Patienten und den Kosten seiner Erkrankung lässt sich aus dem RSA vor 2009 ableiten, mit dem standardisierte Leistungsausgaben für in Disease-Management-Programme (DMP) eingeschlossene Patienten getrennt erfasst wurden. Auffällig bei Patientinnen mit Brustkrebs war, dass die Behandlungskosten mit dem Alter nicht stiegen, sondern deutlich sanken, wobei der Kostengipfel bei Frauen im Alter von etwa 30-40 Jahren lag. Dennoch kalkuliert der neue morbiditätsorientierte RSA die Zuschläge fast immer altersunabhängig, wobei in den onkologischen Bereichen teils hohe Zuschläge (z.B. bei chronischer myeloischer Leukämie (CML) etwa 38 000,- EUR für das Jahr 2015) gezahlt werden. Diese Zuschläge spiegeln die tatsächlichen durchschnittlichen zusätzlichen Kosten pro Patient, aus denen sich durch eine Multiplikation mit der Anzahl der betroffenen Versicherten das Gesamtkostenvolumen ergibt (Abb. 28).

Die größten Zuweisungen aus dem Morbi-RSA - gemessen als Zuweisung pro Versicherten $\times$ Anzahl der Versicherten - erhielten die gesetzlichen Krankenkassen 2016 für Versicherte mit Depression, Insulintherapie und Dialysestatus (Abb. 28). Auch die Zuschläge für die Behandlung von Patienten mit Lungenmetastasen fielen mit 2,55 Milliarden EUR beträchtlich aus und liegen noch über denen für COPD und Herzinsuffizienz.

\section{Wird es noch teurer, wenn alle älter werden?}

Die Lebenserwartung steigt derzeit um mindestens 2 Jahre pro Jahrzehnt; damit wird der Anteil älterer Menschen an der Bevölkerung immer höher. Die Ausgaben für Gesundheit sind in den OECD-Ländern zwischen 1995 und 2009 jährlich im Schnitt um 4,3\% gestiegen, wobei durch die stetige Zunahme älterer Menschen an der Bevölkerung lediglich ein Anstieg der Kosten um 0,5\% pro
Jahr erklärbar ist. Das heißt, nur knapp 10\% der jährlichen Steigerung war darauf zurückzuführen, dass die Bevölkerung im Durchschnitt älter geworden ist. Weitere Einflussfaktoren waren neben der Zunahme von Wohlstand unter anderem auch der medizinische Fortschritt. Diese Faktoren wiederum tragen dazu bei, dass wir älter werden und länger gesund bleiben. Die Zeit, die wir zugleich alt und krank zubringen, muss deshalb nicht zwangsläufig länger werden oder könnte sogar abnehmen.

Dass wir immer gesünder werden, zeigt ein Vergleich der «disability-adjusted life years» (DALYs) in den Global Burden of Disease(GBD)-Studien [97]. In die Berechnung der DALYs wurden alle verlorenen Lebensjahre durch einen vor dem Alter von 86 Jahren eingetretenen Tod («years of life lost»; YLL) sowie die mit Krankheit verbrachten Jahre multipliziert mit einer definierten Krankheitsbeeinträchtigung («years lived with disability»; YLD) einbezogen. Die so gemessenen DALYs sind in Westeuropa seit 1990 deutlich zurückgegangen. Dabei haben sich die krebsbedingten DALYs kaum verändert, während DALYs aufgrund anderer Erkrankungen (vor allem kardiovaskulär bedingt) deutlich rückläufig sind.

Ein weiterer Faktor, der berücksichtigt werden muss, ist der $\mathrm{Zu}$ sammenhang zwischen dem Tod (bzw. dem Alter zum Todeszeitpunkt) und den Gesundheitsausgaben. Am höchsten sind die Kosten in den letzten Lebensjahren, weshalb es Sinn macht, diesen Ausgabenposten getrennt von den übrigen Gesundheitsleistungen zu betrachten. Ein Vergleich zur Krankenhausverweildauer verschiedener Patientengruppen hat gezeigt, dass die Dauer der stationären Aufhalte in den letzten 3 Jahren vor dem Tod deutlich ansteigt [98]. Die längsten Krankenhausaufenthalte (23,4 Tage) hatten die über 85-Jährigen in ihrem letzten Lebensjahr im Vergleich zu 5,4 Tagen bei altersgleichen, aber nicht im Erfassungsjahr verstorbenen Menschen (Studie aus dem Jahr 2002). Ungeachtet dessen fallen noch deutlich mehr Krankenhaustage bei sterbenskranken jungen Menschen an, die ein Vielfaches an Zeit im Krankenhaus verbringen im Vergleich zu jungen Menschen, deren Lebenserwartung nicht derart eingeschränkt ist. Auch andere Studien zeigen, dass in jungen Altersgruppen der Kostenaufwand für den 


\begin{tabular}{llll}
\hline \multicolumn{1}{l}{ Alle } & & \\
\hline Kategorien & $\begin{array}{l}\text { STAs } \\
\text { Single Technol- } \\
\text { ogy Assess- } \\
\text { ments }\end{array}$ & $\begin{array}{l}\text { MTAs } \\
\text { Multiple Technol- } \\
\text { ogy Assessments }\end{array}$ & Total \\
\hline Empfohlen & $160(50 \%)$ & $270(61 \%)$ & $\begin{array}{l}430 \\
(62 \%)\end{array}$ \\
\hline Optimiert & $86(27 \%)$ & $92(21 \%)$ & $\begin{array}{l}178 \\
(23 \%)\end{array}$ \\
\hline Nur in Forschung & $5(2 \%)$ & $23(5 \%)$ & $28(4 \%)$ \\
\hline Nicht empfohlen & $55(17 \%)$ & $60(13 \%)$ & $\begin{array}{l}115 \\
(15 \%)\end{array}$ \\
\hline Cancer Drugs Fund & $11(4 \%)$ & - & $11(1 \%)$ \\
\hline Total & $317(100 \%)$ & $445(100 \%)$ & $\begin{array}{l}762 \\
(100 \%)\end{array}$ \\
\hline
\end{tabular}

Abb. 29. Bewertungsergebnisse des NICE.

Lebenserhalt deutlich höher ist als in den älteren Gruppen - für die jungen Menschen werden alle nur möglichen Therapieoptionen ausgeschöpft, was ja nachvollziehbar ist. Es ist deshalb anzunehmen, dass sich die hohen Krankheitskosten, die heute ab etwa 80 Jahren auftreten, mit steigender Lebenserwartung weiter nach hinten verschieben.

Wenn die Kosten für das letzte Lebensjahr herausgerechnet werden, müssen die Vorhersagen bezüglich der für die nächsten Jahre anstehenden Kostenentwicklung modifiziert werden. Der reine Alterseffekt dürfte zu einer Verschiebung der Kosten zulasten der Ältesten führen, aber nicht unbedingt zu einem Kostenanstieg. Dieser ist vielmehr auf andere, nichtdemografische Faktoren zurückzuführen, die es zu beeinflussen gilt. Tatsächlich geht die OECD von weiter steigenden Kosten aus, sie sind aber nur zu einem Anteil von 0,4\% (Prognose für 2030) bzw. 0,8\% (Prognose für 2060) auf die zunehmende Alterung der Bevölkerung zurückzuführen. Um die Kosten zu senken, müsste also bei anderen kostentreibenden Faktoren gespart werden und/oder der Zugang zu Leistungen - insbesondere den nicht wirksamen bzw. angemessenen - begrenzt werden. Dies hieße, stärker als bisher auf die Kosteneffektivität zu achten, wie dies in Großbritannien dem National Institute for Health and Care Excellence (NICE) übertragen wurde. Das NICE bewertet die ökonomische Effizienz von Gesundheitsleistungen anhand von QALY-Werten (QALYs = quality-adjusted life years), ein Outcome-Maß mit Berücksichtigung von Lebenserwartung und Lebensqualität. Entsprechend dieser KostenNutzen-Bewertung wird eine Kostenübernahme der jeweiligen Leistung durch das staatliche Gesundheitswesen generell oder optimiert (d.h. auf die kosteneffektiven Indikationen eingeschränkt) empfohlen, für Forschungszwecke empfohlen oder nicht empfohlen (Abb. 29). Für Krebstherapien gibt es einen Sonderfonds.

Als Fazit bleibt festzuhalten, dass ältere Patienten im Querschnitt zwar teurer sind, aber dies liegt daran, dass sie häufiger krank sind, und nicht daran, dass ihre Behandlung kostenintensiver als bei jüngeren ist (eher ist das Gegenteil der Fall). Auch bei der Entwicklung der Gesundheitsausgaben spielt die Alterung eine verhältnismäßig kleine Rolle. Dennoch müssen wir die Kosten im Blick behalten, etwa durch Überlegungen zur Kosteneffektivität ausgewählter Leistungsangebote.

\section{Disclosure Statement}

Diana Lüftner erhielt Honorare für Vorträge und beraterliche Tätigkeit von Amgen, Roche, Novartis, Pfizer, Daiichi Sanchyo. Carsten Bokemeyer erhielt als Mitglied der AG Geriatrische Onkologie Forschungsunterstützung von Janssen-Cilag für die Untersuchungen zum IN-GHO-Register.

\section{References}

1 Ferlay J, et al.: GLOBOCAN 2012 v1.0, Cancer Incidence and Mortality Worldwide: IARC CancerBase No. 11. Lyon, International Agency for Research on Cancer (IARC), http://globocan.iarc.fr, 2013.

2 Robert Koch-Institut (Hrsg), Gesellschaft der epidemiologischen Krebsregister in Deutschland e.V. (Hrsg): Krebs in Deutschland für 2013/2014, ed 11. Berlin, Robert Koch-Institut, 2017.

3 Smetana $\mathrm{K} \mathrm{Jr}$, et al.: Ageing as an important risk factor for cancer. Anticancer Res 2016;36:5009-5017.

4 Bray F, et al.: Cancer Incidence in Five Continents, vol XI (electronic version). Lyon, International Agency for Research on Cancer (IARC), http://ci5.iarc.fr, 2017 (letzter Zugriff: 06.04.2018)

5 Quante AS et al.: Projections of cancer incidence and cancer-related deaths in Germany by 2020 and 2030 . Cancer Med 2016;5:2649-2656.

6 www.tumorregister-muenchen.de.

7 Schmidt M, Schubert-Fritschle G, Engel J: Epidemiologie des Lungenkarzinoms; in Huber R (Hrsg): Tumoren der Lunge und des Mediastinums. Empfehlungen zur Diagnostik, Therapie und Nachsorge, ed 11. München, W. Zuckschwerdt Verlag, Tumorzentrum München, 2017
8 Schlesinger-Raab A, Werner J, Friess H, Hölzel D, Engel J: Age and outcome in gastrointestinal cancers: a population-based evaluation of oesophageal, gastric and colorectal cancer. Visc Med 2017;33:245-253.

9 Anderson JR, Cain KC, Gelber RD: Analysis of survival by tumor response. J Clin Oncol 1983;1:710-719.

10 Wilson J, et al.: Principles and practice of screening for disease. Geneva, World Health Organization, www. who.int/iris/handle/10665/37650, 1968.

11 Chen Y, Brock G, Wu D: Estimating key parameters in periodic breast cancer screening - application to the Canadian National Breast Screening Study data. Cancer Epidemiol 2010;34:429-433.

12 Taghipour S, et al.: Parameter estimates for invasive breast cancer progression in the Canadian National Breast Screening Study. Br J Cancer 2013;108:542-548.

13 Draisma G, van Rosmalen J: A note on the catch-up time method for estimating lead or sojourn time in prostate cancer screening. Stat Med 2013;32:33323341.

14 Gesellschaft der epidemiologischen Krebsregister in Deutschland e.V. (GEKID): GEKID-Atlas, Stand Juli 2017. www.gekid.de
15 Schoen RE; PLCO Project Team: Colorectal-cancer incidence and mortality with screening flexible sigmoidoscopy. N Engl J Med 2012;366:2345-2357.

16 Altenhofen L, et al.: Wissenschaftliche Begleitung von Früherkennungskoloskopien in Deutschland Jahresbericht 2010. Berlin, Zentralinstitut für die kassenärztliche Versorgung (Hrsg), 2012.

17 S3-Leitlinie Kolorektales Karzinom, Langversion 2.0 November 2017, AWMF-Registernummer: 021/007OL. www.awmf.org/leitlinien/detail/ll/021-007OL.html.

18 Balmana J, Balaguer F, Cervantes A, Arnold D; ESMO Guidelines Working Group: Familial colorectal cancer risk: rectal cancer: ESMO clinical practice guidelines. Ann Oncol 2013;24(suppl 6):vi73-v80.

19 Gøtzsche PC, Jørgensen KJ: Screening for breast cancer with mammography. Cochrane Database Syst Rev 2013;(6):CD001877.

20 US Preventive Services Task Force et al.: Screening for colorectal cancer: US Preventive Services Task Force recommendation statement. JAMA 2016;315:25642575

21 Deutsches Konsortium für hereditären Brust- und Eierstockskrebs, www.konsortium-familiaerer-brustkrebs.de/. 
22 Andriole GL; PLCO Project Team: Mortality results from a randomized prostate-cancer screening trial. $\mathrm{N}$ Engl J Med 2009;360:1310-1319.

23 Schröder FH, et al.: Eleven-year outcome of patients with prostate cancers diagnosed during screening after initial negative sextant biopsies. Eur Urol 2010;57: 256-266.

24 Hugosson J, et al.: Mortality results from the Göteborg randomised population-based prostate-cancer screening trial. Lancet Oncol 2010;11:725-732.

25 Sandblom G, et al.: Randomised prostate cancer screening trial: 20 year follow-up. BMJ 2011; 342:d1539.

26 Breitbart EW, et al.: Systematic skin cancer screening in Northern Germany. J Am Acad Dermatol 2012;66: 11

27 Eisemann N, et al.: Inzidenz des malignen Melanoms und Veränderung der stadienspezifischen Inzidenz nach Einführung eines Hautkrebsscreenings in Schleswig-Holstein. Bundesgesundheitsbl Gesundheitsforsch Gesundheitsschutz 2014;57:7.

28 Krebsfrüherkennung in Deutschland, 2014. Evidenz aktueller Stand - Perspektiven. Gesundheitspolitische Schriftenreihe der DGHO, Band 4, 2014. www.dgho. de/publikationen/schriftenreihen/krebsfrueherkennung.

29 Gohagan JK, et al.: Final results of the Lung Screening Study, a randomized feasibility study of spiral CT versus chest X-ray screening for lung cancer. Lung Cancer 2005;47:9-15

30 Infante $\mathrm{M}$, et al.: A randomized study of lung cancer screening with spiral computed tomography: threeyear results from the DANTE trial. Am J Respir Crit Care Med 2009; 180:445-453.

31 Saghir Z, et al.: CT screening for lung cancer brings forward early disease. The randomised Danish Lung Cancer Screening Trial: status after five annual screening rounds with low-dose CT. Thorax 2012;67:296301

32 The National Lung Screening Trial Research Team: Reduced lung-cancer mortality with low-dose computed tomographic screening. N Engl J Med 2011;365 395-409.

33 Armaroli P, et al.: European Code against Cancer, ed 4 Cancer screening. Cancer Epidemiol 2015;39(suppl 1):S139-S152

34 Ries LAG, et al. (eds): SEER Cancer Statistics Review 1975-2001. Bethesda, National Cancer Institute, https://seer.cancer.gov/csr/1975_2001/, 2004.

35 Yanci R: Cancer burden in the aged: an epidemiologic and demographic overview. Cancer 1997;80:12731283

36 Thurmes P, et al.: Comorbid conditions and survival in unselected, newly diagnosed patients with chronic lymphocytic leukemia. Leuk Lymphoma 2008;49:49-

37 da Cunha-Bang C, et al.: Improved survival for patients diagnosed with chronic lymphocytic leukemia in the era of chemo-immunotherapy: a Danish population-based study of 10455 patients. Blood Cancer J 2016;6:e499.

38 Gribben JG: One step back but 2 steps forward. Blood 2009;114:3359-3360

39 Balducci L, Extermann M: Management of cancer in the older person: a practical approach. Oncologist 2000;5:224-237.

40 Linn BS, Linn MW, Gurel L: Cumulative illness rating scale. J Am Geriatr Soc 1968;16:622-626.

41 Hallek M, et al.: Addition of rituximab to fludarabine and cyclophosphamide in patients with chronic lymphocytic leukaemia: a randomised, open-label, phase 3 trial. Lancet 2010;376:1164-1174

42 Tam E, et al.: Efficacy of combination fludarabine, cyclophosphamide and rituximab in patients with CLL. J Clin Oncol 2007;25:A7008.
43 Eichhorst B; et al: First-line chemoimmunotherapy with bendamustine and rituximab versus fludarabine, cyclophosphamide, and rituximab in patients with advanced chronic lymphocytic leukaemia (CLL10): an international, open-label, randomised, phase 3, noninferiority trial. Lancet Oncol 2016;17:928-942.

44 Keating MJ, et al.: Early results of a chemoimmunotherapy regimen of fludarabine, cyclophosphamide, and rituximab as initial therapy for chronic lymphocytic leukemia. J Clin Oncol 2005;23:4079-4088.

45 Ferrajoli A, et al.: Treatment of patients with CLL 70 years old and older: a single center experience of 142 patients. Leuk Lymphoma 2005;46:S87.

46 Eichhorst BF, et al.: First-line therapy with fludarabine compared with chlorambucil does not result in a major benefit for elderly patients with advanced chronic lymphocytic leukemia. Blood 2009;114:3382-3391.

47 Catovsky D, Else M, Richards S: Chlorambucil - still not bad: a reappraisal. Clin Lymphoma Myeloma Leuk 2011;11(suppl 1):S2-S6.

48 Mössner E, et al.: Increasing the efficacy of CD20 antibody therapy through the engineering of a new type II anti-CD20 antibody with enhanced direct and immune effector cell-mediated B-cell cytotoxicity. Blood 2010;115:4393-4402.

49 Patz M, et al.: Comparison of the in vitro effects of the anti-CD20 antibodies rituximab and GA101 on chronic lymphocytic leukaemia cells. Br J Haematol 2011;152:295-306.

50 Goede V, et al.: Obinutuzumab plus chlorambucil in patients with CLL and coexisting conditions. N Engl J Med 2014;370:1101-1110.

51 Tedeschi A, et al.: Results from the international, randomized phase 3 study of ibrutinib versus chlorambucil in patients 65 years and older with treatment-naïve CLL/SLL (RESONATE-2 ${ }^{\mathrm{TM}}$ ). ASH Meeting 2015; abstr 495

52 Burger JA, et al.: Ibrutinib as initial therapy for patients with chronic lymphocytic leukemia. N Engl J Med 2015;373:2425-2437.

53 Furman RR, et al.: Idelalisib and rituximab in relapsed chronic lymphocytic leukemia. N Engl J Med 2014; 370:997-1007.

54 Sharman JP, et al.: Second interim analysis of a phase 3 study of idelalisib (ZYDELIG ${ }^{\circledR}$ ) plus rituximab ${ }^{\circledR}$ for relapsed chronic lymphocytic leukemia (CLL): efficacy analysis in patient subpopulations with $\operatorname{del}(17 \mathrm{p})$ and other adverse prognostic factors. Blood 2014;124:abstr 330

55 Onkopedia-Leitlinie Kolonkarzinom, www.onkopedia. com/de/onkopedia/guidelines/kolonkarzinom/@@view/ html/index.html, Stand August 2017.

56 Pox CP, et al.: Efficacy of a nationwide screening colonoscopy program for colorectal cancer. Gastroenterology 2012;142:1460-1467.

57 Andre T, Boni C, et al.: Oxaliplatin, fluorouracil, and leucovorin as adjuvant treatment for colon cancer. $\mathrm{N}$ Eng J Med 2004;350:2343-2351.

58 Yothers G, et al.: Oxaliplatin as adjuvant therapy for colon cancer: updated results of NSABP C-07 trial, including survival and subset analyses. J Clin Oncol 2011;29:3768-3774.

59 Schmoll HJ, et al.: Capecitabine plus oxaliplatin com pared with fluorouracil/folinic acid as adjuvant therapy for stage III colon cancer: final results of the NO16968 randomized controlled phase III trial. J Clin Oncol 2015;33:3733-3740.

60 Cunningham D, et al.: Bevacizumab plus capecitabine versus capecitabine alone in elderly patients with previously untreated metastatic colorectal cancer (AVEX): an open-label, randomised phase 3 trial. Lancet Oncol 2013;14:1077-1085.
61 van Tuil T, et al.: Systematic review and meta-analysis of liver resection for colorectal metastases in elderly patients. Dig Surg 2018, in press. DOI: 10.1159/000487274

62 Chang CC, et al.: Molecular and clinicopathological differences by age at the diagnosis of colorectal cancer. Int J Mol Sci 2017; 18:pii: E1441.

63 Empfehlungen der AGO Kommission Mamma. Diagnostik und Therapie von Patientinnen mit primärem und metastasiertem Brustkrebs, Version 2018.1. www. ago-online.de/fileadmin/downloads/leitlinien/ mamma/2018-03/Gesamt_deutsch/Alle_aktuellen_ Empfehlungen_2018.pdf.

64 Rugo HS, et al.: Long-term follow-up of CALGB 40502/NCCTG N063H (Alliance): A randomized phase III trial of weekly paclitaxel (P) compared to weekly nanoparticle albumin bound nab-paclitaxe (NP) or ixabepilone (Ix) +/- bevacizumab as first-line therapy for locally recurrent or metastatic breast cancer (MBC). SABCS 2017;abstr GS3-06.

65 Bardia A, et al.: Sacituzumab govitecan (IMMU-132) an anti-Trop-2-SN-38 antibody-drug conjugate, as $\geq 3$ rd-line therapeutic option for patients with relapsed/refractory metastatic triple-negative breast cancer (mTNBC): efficacy results. SABCS 2017; abstr GS1-07.

66 Kuchenbaecker KB, et al.: Risks of breast, ovarian, and contralateral breast cancer for BRCA1 and BRCA2 mutation carriers. JAMA 2017;317:2402-2416.

67 Robson ME, et al.: OlympiAD: Phase III trial of olaparib monotherapy versus chemotherapy for patients (pts) with HER2-negative metastatic breast cancer $(\mathrm{mBC})$ and a germline BRCA mutation (gBRCAm). J Clin Oncol 2017;35(suppl 18):LBA4.

68 Litton J, et al.: EMBRACA: A phase 3 trial comparing talazoparib, an oral PARP inhibitor, to physician's choice of therapy in patients with advanced breast cancer and a germline BRCA mutation. SABCS 2017;abstr GS6-07.

69 Moulder SL, et al.: Phase I study of ONT-380, a HER2 inhibitor, in patients with HER2+-advanced solid tumors, with an expansion cohort in HER2+ metastatic breast cancer (mBC). Clin Cancer Res 2017;23:35293536

70 Loi S, et al.: Phase Ib/II study evaluating safety and efficacy of pembrolizumab and trastuzumab in patients with trastuzumab-resistant HER2-positive metastatic breast cancer: results from the PANACEA (IBCSG 45-13/BIG 4-13/KEYNOTE-014) study. Cancer Research 78(4 suppl):GS2-06-GS2-06.

71 Doi T, et al.: Single agent activity of DS-8201a, a HER2-targeting antibody-drug conjugate, in heavily pretreated HER2 expressing solid tumors. J Clin Oncol 2017;35(suppl 15):abstr 108.

72 Hortobagyi GN, et al.: Ribociclib as first-line therapy for HR-positive, advanced breast cancer. N Engl J Med 2016;375:1738-1748.

73 Finn RS, et al.: The cyclin-dependent kinase 4/6 inhibitor palbociclib in combination with letrozole versus letrozole alone as first-line treatment of oestrogen receptor-positive, HER2-negative, advanced breast cancer (PALOMA-1/TRIO-18): a randomised phase 2 study. Lancet Oncol 2015;16:25-35.

74 Cristofanilli M, et al.: Fulvestrant plus palbociclib versus fulvestrant plus placebo for treatment of hormonereceptor-positive, HER2-negative metastatic breast cancer that progressed on previous endocrine therapy (PALOMA-3): final analysis of the multicentre, double-blind, phase 3 randomised controlled trial. Lancet Oncol 2016;17:425-439.

75 Singh H, et al.: A U.S. food and drug administration pooled analysis of outcomes of older women with hormone-receptor positive metastatic breast cancer treated with a CDK4/6 inhibitor as initial endocrine based therapy. SABCS 2017;abstr GS5-06. 
76 Abdelhady AA, et al.: Ribociclib dose recommendations for potential pharmacokinetic drug interaction and in special patient populations with organ impairment. SABCS 2017;abstr P1-14-05.

77 DGHO e.V. (Hrsg): Herausforderung demografischer Wandel. Bestandsaufnahme und künftige Anforderungen an die onkologische Versorgung. Gesundheitspolitische Schriftenreihe der DGHO, Band 1, Februar 2013.

78 Statistisches Bundesamt: Statistisches Jahrbuch 2017 www.destatis.de/DE/Publikationen/StatistischesJahrbuch/Bevoelkerung.pdf?_blob=publicationFile.

79 Edwards BK, et al.: Annual report to the nation on the status of cancer, 1973-1999, featuring implications of age and aging on U.S. cancer burden. Cancer 2002;94: 2766-2792.

80 Smith BD, et al.: Improvement in breast cancer outcomes over time: are older women missing out? J Clin Oncol 2011;29:4647-4653.

81 Liu Y, et al.: Expression of p16(INK4a) in peripheral blood T-cells is a biomarker of human aging. Aging Cell 2009;8:439-448.

82 Elkin EB, et al.: Desire for information and involvement in treatment decisions: elderly cancer patients preferences and their physicians' perceptions. J Clin Oncol 2007;25:5275-5280

83 Koroukian SM, et al.: Comorbidity, disability, and geriatric syndromes in elderly cancer patients receiving home health care. J Clin Oncol 2006;24:2304-2310.
84 Caillet $\mathrm{P}$, et al.: Comprehensive geriatric assessment in the decision-making process in elderly patients with cancer: ELCAPA study. J Clin Oncol 2011;29:36363642 .

85 Extermann M, et al.: Predicting the risk of chemotherapy toxicity in older patients: the Chemotherapy Risk Assessment Scale for High-Age Patients (CRASH) score. Cancer 2012;118:3377-3386.

86 Soubeyran P, et al.: Predictors of early death risk in older patients treated with first-line chemotherapy for cancer. J Clin Oncol 2012;30:1829-1834.

87 Lichtman SM, et al.: International Society of Geriatric Oncology (SIOG) recommendations for the adjustment of dosing in elderly cancer patients with renal insufficiency. Eur J Cancer 2007;43:14-34.

88 Hurria A, et al.: Predicting chemotherapy toxicity in older adults with cancer: a prospective multicenter study. J Clin Oncol 2011;29:3457-3465.

89 Meinertz T, Kähler J: Polypharmakotherapie. ein Problem der Evidence-based Medicine. Arzneimitteltherapie 2005;23:176-180.

90 Amann U, et al.: Prescribing of potentially inappropriate medications for the elderly: an analysis based on the PRISCUS list. Dtsch Arztebl Int 2012;109:69-75.

91 Seymour MT, et al.: Chemotherapy options in elderly and frail patients with metastatic colorectal cancer (MRC FOCUS2): an open-label, randomised factorial trial. Lancet 2011;377:1749-1759.
92 Goede V, et al.: Obinutuzumab as frontline treatment of chronic lymphocytic leukemia: updated results of the CLL11 study. Leukemia 2015;29:1602-1604.

93 Stilgenbauer S, et al.: Gene mutations and treatment outcome in chronic lymphocytic leukemia: results from the CLL8 trial. Blood 2014;123:3247-3254.

94 International CLL-IPI Working Group: An international prognostic index for patients with chronic lymphocytic leukaemia (CLL-IPI): a meta-analysis of individual patient data. Lancet Oncol 2016;17:779-790.

95 Göpffarth D: Die Zukunft der DMP im direkt morbiditätsorientierten Risikostrukturausgleich; in: Newsletter der Deutschen Gesellschaft für Disease Management, Juli 2008.

96 Barnett K, et al.: Epidemiology of multimorbidity and implications for health care, research, and medical education: a cross-sectional study. Lancet 2012;380:3743.

97 GBD 2016 Mortality Collaborators: The global, regional, and national under-5 mortality, adult mortality, age-specific mortality, and life expectancy, 19702016: a systematic analysis for the Global Burden of Disease Study 2016. Lancet 2017;390:1084-1150.

98 Busse R, et al.: Use of acute hospital beds does not increase as the population ages - results from a 7-year cohort study in Germany. J Epidemiol Community Health 2002;56: 289-293. 